\title{
A community perspective on the concept of marine holobionts: current status, challenges, and future directions
}

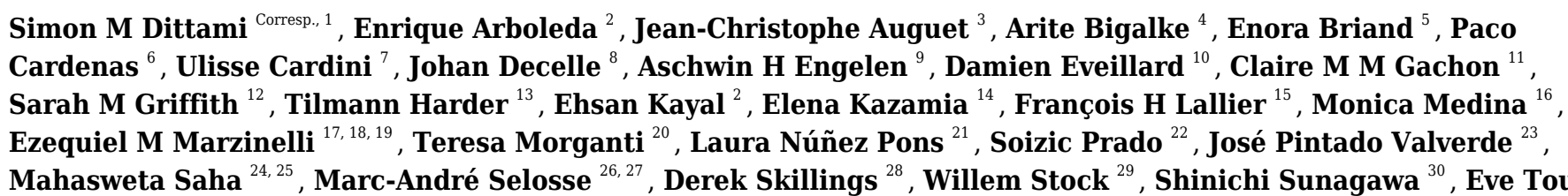
${ }_{31}$, Alexey Vorobev ${ }^{32}$ 'Catherine Leblanc ${ }^{\text {Corresp., } 1}$, Fabrice Not ${ }^{15}$

1 Integrative Biology of Marine Models (LBI2M), Station Biologique de Roscoff, Sorbonne Université, CNRS,, Roscoff, France

2 FR2424, Station Biologique de Roscoff, Sorbonne Université, CNRS, Roscoff, France

3 MARBEC, Université de Montpellier, CNRS, IFREMER, IRD, Montpellier, France

4 Institute for Inorganic and Analytical Chemistry, Bioorganic Analytics, Friedrich-Schiller-Universität Jena, Jena, Germany

5 Laboratoire Phycotoxines, Ifremer, Nantes, France

6 Pharmacognosy, Dept. of Medicinal Chemistry, Uppsala University, Uppsala, Sweden

7 Integrative Marine Ecology Dept, Stazione Zoologica Anton Dohrn, Napoli, Italy

8 Laboratoire de Physiologie Cellulaire et Végétale, Université Grenoble Alpes, CNRS, CEA, INRA, Grenoble, France

9 CCMAR, Universidade do Algarve, Faro, Portugal

10

Laboratoire des Sciences Numériques de Nantes (LS2N), Université de Nantes, CNRS, Nantes, France

11 Scottish Marine Institute, Scottish Association for Marine Science, Oban, United Kingdom

12 School of Science and the Environment, Manchester Metropolitan University, Manchester, United Kingdom

13 University of Bremen, Bremen, Germany

14 Institut de Biologie, ENS, Paris, France

15 Adaptation and Diversity in the Marine Environment, Station Biologique de Roscoff, Sorbonne Université, CNRS, Roscoff, France

16

Dept. of Biology, Pennsylvania State University, University Park, United States of America

17 School of Life and Environmental Sciences, The University of Sydney, Sydney, Australia

18 Singapore Centre for Environmental Life Sciences Engineering, Nanyang Technological University, Singapore, Singapore

19 Sydney Institute of Marine Science, Mosman, Australia

20 Max Planck Institute for Marine Microbiology, Bremen, Germany

21 Section Biology and Evolution of Marine Organisms, Stazione Zoologica Anton Dohrn, Napoli, Italy

22 Molecules of Communication and Adaptation of Microorganisms (UMR 7245), National Museum of Natural History, CNRS, Paris, France

23 Instituto de Investigaciones Marinas, Vigo, Spain

24 Benthic Ecology, Helmholtz Center for Ocean Research, Kiel, Germany

25 Marine Ecology and Biodiversity, Plymouth Marine Laboratory, Plymouth, United Kingdom

26

National Museum of Natural History, Département Systématique et Evolution, Paris, France

27 Faculty of Biology, University of Gdansk, Gdansk, Poland

28 Philosophy Dept, University of Pennsylvania, Philadelphia, United States of America

29 Laboratory of Protistology \& Aquatic Ecology, Dept. of Biology, Ghent University, Ghent, Belgium

30 Dept. of Biology, Institute of Microbiology and Swiss Institute of Bioinformatics, ETH, Zürich, Switzerland

31 IHPE UMR 5244, Univ. Perpignan Via Domitia, CNRS, IFREMER, Univ. Montpellier, Perpignan, France

32 CEA - Institut de Biologie François Jacob, Genoscope, Evry, France

Peer) reviewing PDF | (2020:09:53081:1:2:NEW 22 Dec 2020) 
Corresponding Authors: Simon M Dittami, Catherine Leblanc

Email address: simon.dittami@sb-roscoff.fr, leblanc@sb-roscoff.fr

Host-microbe interactions play crucial roles in marine ecosystems. However, we still have very little understanding of the mechanisms that govern these relationships, the evolutionary processes that shape them, and their ecological consequences. The holobiont concept is a renewed paradigm in biology that can help to describe and understand these complex systems. It posits that a host and its associated microbiota with which it interacts, form a holobiont, and have to be studied together as a coherent biological and functional unit to understand its biology, ecology, and evolution. Here we discuss critical concepts and opportunities in marine holobiont research and identify key challenges in the field. We highlight the potential economic, sociological, and environmental impacts of the holobiont concept in marine biological, evolutionary, and environmental sciences. Given the connectivity and the unexplored biodiversity specific to marine ecosystems, a deeper understanding of such complex systems requires further technological and conceptual advances, e.g. the development of controlled experimental model systems for holobionts from all major lineages and the modeling of (info)chemical-mediated interactions between organisms. Here we propose that one significant challenge is to bridge cross-disciplinary research on tractable model systems in order to address key ecological and evolutionary questions. This first step is crucial to decipher the main drivers of the dynamics and evolution of holobionts and to account for the holobiont concept in applied areas, such as the conservation, management, and exploitation of marine ecosystems and resources, where practical solutions to predict and mitigate the impact of human activities are more important than ever. 
4 A community perspective on the concept of 5 marine holobionts: current status, challenges, 6 and future directions

7

8 The Holomarine working group ${ }^{*}$ : Simon M. Dittami ${ }^{1}$, Enrique Arboleda ${ }^{2}$, Jean-

9 Christophe Auguet $^{3}$, Arite Bigalke ${ }^{4}$, Enora Briand ${ }^{5}$, Paco Cárdenas ${ }^{6}$, Ulisse Cardini ${ }^{7}$, 10 Johan Decelle ${ }^{8}$, Aschwin H. Engelen ${ }^{9}$, Damien Eveillard ${ }^{10}$, Claire M.M. Gachon ${ }^{11}$,

Sarah M. Griffiths ${ }^{12}$, Tilmann Harder ${ }^{13}$, Ehsan Kayal2 ${ }^{2}$, Elena Kazamia ${ }^{14}$, Francois $\mathrm{H}$. Lallier $^{15}$, Mónica Medina ${ }^{16}$, Ezequiel M. Marzinelli ${ }^{17}$, Teresa Morganti ${ }^{18}$, Laura Núñez Pons ${ }^{19}$, Soizic Prado ${ }^{20}$, José Pintado Valverde ${ }^{21}$, Mahasweta Saha ${ }^{22}$, MarcAndré Selosse ${ }^{23}$, Derek Skillings ${ }^{24}$, Willem Stock ${ }^{25}$, Shinichi Sunagawa ${ }^{26}$, Eve Toulza $^{27}$, Alexey Vorobev ${ }^{28}$, Catherine Leblanc ${ }^{1}$, and Fabrice Not ${ }^{15}$

\footnotetext{
* This working group gathers 31 scientists from ten different countries, with expertise covering different scientific disciplines including philosophy, evolution, computer sciences, marine biology, ecology, chemistry, and microbiology, who participated in a workshop on marine holobionts, organized at the Roscoff Biological Station in March 2018. Their aim was to exchange ideas regarding key concepts and opportunities in marine holobiont research, to start structuring the community, and to identify and tackle key challenges in the field.
}

1 Sorbonne Université, CNRS, Integrative Biology of Marine Models (LBI2M), Station Biologique de Roscoff, 29680 Roscoff, France

2 Sorbonne Université, CNRS, FR2424, Station Biologique de Roscoff, 29680 Roscoff, France

3 MARBEC, Université de Montpellier, CNRS, IFREMER, IRD, Montpellier, France

4 Institute for Inorganic and Analytical Chemistry, Bioorganic Analytics, Friedrich-Schiller-Universität Jena, Lessingstrasse 8, D-07743 Jena, Germany

5 Ifremer, Laboratoire Phycotoxines, 44311 Nantes, France

6 Pharmacognosy, Dept. of Medicinal Chemistry, Uppsala University, BMC Box 574, 75123 Uppsala, Sweden

7 Integrative Marine Ecology Dept., Stazione Zoologica Anton Dohrn, Napoli, Italy

8 Laboratoire de Physiologie Cellulaire et Végétale, Université Grenoble Alpes, CNRS, CEA, INRA; 38054, Grenoble Cedex 9, France

9 CCMAR, Universidade do Algarve, Campus de Gambelas, Faro, Portugal

10 Université de Nantes, CNRS, Laboratoire des Sciences Numériques de Nantes (LS2N), 44322 Nantes, France

11 Scottish Association for Marine Science, Scottish Marine Institute, PA37 1QA Oban, UK

12 School of Science and the Environment, Manchester Metropolitan University, Manchester, UK

13 University of Bremen, Leobener Strasse 6, 28359 Bremen, Germany

14 Institut de Biologie de l'ENS, 46 rue d'Ulm, 75005 Paris, France

15 Sorbonne Université, CNRS, Adaptation and Diversity in the Marine Environment, Station Biologique de Roscoff, 29680 Roscoff, France

16 Dept. of Biology, Pennsylvania State University, University Park PA 16801, USA 
4417 The University of Sydney, School of Life and Environmental Sciences, Sydney, NSW 2006, Australia; 45 Singapore Centre for Environmental Life Sciences Engineering, Nanyang Technological University, 46 Singapore; Sydney Institute of Marine Science, Mosman, NSW 2088, Australia

4718 Max Planck Institute for Marine Microbiology, Celsiusstraße 1, 28359 Bremen, Germany

4819 Section Biology and Evolution of Marine Organisms (BEOM), Stazione Zoologica Anton Dohrn (SZN), 49 Villa Comunale, 80121, Napoli, Italy

5020 Molecules of Communication and Adaptation of Microorganisms (UMR 7245), National Museum of $51 \quad$ Natural History, CNRS, 57 rue Cuvier, 75005 Paris, France

5221 Instituto de Investigaciones Marinas (IIM-CSIC), Eduardo Cabello 6, 36208 Vigo, Galicia, Spain

5322 Benthic Ecology, Helmholtz Center for Ocean Research, Düsternbrooker Weg 20, 24105 Kiel, Germany;

54 Marine Ecology and Biodiversity, Plymouth Marine Laboratory, PL1 3DH Plymouth, UK.

5523 Département Systématique et Evolution, Muséum national d'Histoire naturelle, UMR 7205 ISYEB, CP

5650,45 rue Buffon, Paris 75005, France; Faculty of Biology, University of Gdansk, ul. Wita Stwosza 59, 57 80-308, Gdansk, Poland

5824 Philosophy Dept., University of Pennsylvania, 249 S. 36th Street, Philadelphia PA 19104-6304, USA

5925 Laboratory of Protistology \& Aquatic Ecology, Dept. of Biology, Ghent University, Krijgslaan 281-S8, 609000 Ghent, Belgium

61

62

63

64

65

26 Dept. of Biology, Institute of Microbiology and Swiss Institute of Bioinformatics, ETH Zürich, VladimirPrelog-Weg 4, 8093 Zürich, Switzerland

27 Univ. Perpignan Via Domitia, IHPE UMR 5244, CNRS, IFREMER, Univ. Montpellier, 66000 Perpignan, France

67

28 CEA - Institut de Biologie François Jacob, Genoscope, 2 Rue Gaston Crémieux, 91057 Evry, France 


\section{Abstract}

71

Host-microbe interactions play crucial roles in marine ecosystems. However, we still have very little understanding of the mechanisms that govern these relationships, the evolutionary processes that shape them, and their ecological consequences. The holobiont concept is a renewed paradigm in biology that can help to describe and understand these complex systems. It posits that a host and its associated microbiota with which it interacts, form a holobiont, and have to be studied together as a coherent biological and functional unit to understand its biology, ecology, and evolution. Here we discuss critical concepts and opportunities in marine holobiont research and identify key challenges in the field. We highlight the potential economic, sociological, and environmental impacts of the holobiont concept in marine biological, evolutionary, and environmental sciences. Given the connectivity and the unexplored biodiversity specific to marine ecosystems, a deeper understanding of such complex systems requires further technological and conceptual advances, e.g. the development of controlled experimental model systems for holobionts from all major lineages and the modeling of (info)chemical-mediated interactions between organisms. Here we propose that one significant challenge is to bridge cross-disciplinary research on tractable model systems in order to address key ecological and evolutionary questions. This first step is crucial to decipher the main drivers of the dynamics and evolution of holobionts and to account for the holobiont concept in applied areas, such as the conservation, management, and exploitation of marine ecosystems and resources, where practical solutions to predict and mitigate the impact of human activities are more important than ever.

\section{Glossary*}

* If no other examples of the use of each term are cited below, the definition was based on the online version of the Merriam-Webster dictionary (2019, https://www.merriam-webster.com/) or the Oxford dictionary (2020, https://www.lexico.com/)

Anna Karenina principle - several factors can cause a system to fail, but only a narrow range of parameters characterizes a working system; based on the first sentence of Leo Tolstoy's "Anna Karenina" (1878): "Happy families are all alike; every unhappy family is unhappy in its own way" (Zaneveld, McMinds, et al. 2017).

Aposymbiotic culture - a culture of a host or a symbiont without its main symbiotic partner(s) (e.g. Kelty and Cook 1976). In contrast to gnotobiotic cultures, aposymbiotic cultures are usually not germfree.

Biological control (biocontrol) - methods for controlling diseases or pests by introducing or supporting natural enemies of the former (see e.g. Hoitink and Boehm 1999).

Biomonitoring - the use of living organisms as quantitative indicator for the health of an environment or ecosystem (Holt and Miller 2010).

Community assembly process - the processes that shape community composition in a given habitat, according to Nemergut et al. (2013) the four main forces relevant for community assembly are evolutionary diversification, dispersal, selection, and ecological drift.

Dysbiosis - microbial imbalance in a symbiotic community that affects the health of the host (Egan and Gardiner 2016). 
109

110

111

112

113

114

115

116

117

118

119

120

121

122

123

124

125

126

127

128

129

130

131

132

133

134

135

136

137

138

139

140

141

142

143

144

145

146

147

148

149

150

151

152

153

154

155

156

Ecological process - the processes responsible for the functioning and dynamics of ecosystems including biogeochemical cycles, community assembly processes, interactions between organisms, and climatic processes (see e.g. Bennett et al. 2009).

Ecosystem services - any direct or indirect benefits that humans can draw from an ecosystem; they include provisioning services (e.g. food), regulating services (e.g. climate), cultural services (e.g. recreation), and supporting services (e.g. habitat formation) (Millennium Ecosystem Assessment Panel 2005).

Ectosymbiosis - a symbiotic relationship in which symbionts live on the surface of a host. This includes, for instance, algal biofilms or the skin microbiome (Nardon and Charles 2001).

Emergent property - a property of complex systems (e.g. holobionts), which arises from interactions between the components and that is not the sum of the component properties (see e.g. Theis 2018).

Endosymbiosis (sometimes also referred to more precisely as endocytobiosis; Nardon and Charles 2001) - a symbiotic relationship in which a symbiont lives inside the host cells; prominent examples are mitochondria, plastids/photosymbionts, or nitrogen fixing bacteria in plant root nodules. See also ectosymbioisis.

Gnotobiosis - the condition in which all organisms present in a culture can be controlled, i.e. germ-free (axenic) organisms or organisms with a controlled community of symbionts. Gnotobiotic individuals may be obtained e.g. by surgical removal from the mother (vertebrates) or by surface sterilization of seeds (plants) and subsequent handling in a sterile environment and possible inoculation with selected microbes (Hale, Lindsey, et al. 1973, Williams 2014).

Holism - the theory that parts of a whole are in intimate interconnection, such that they cannot exist independently of the whole, or cannot be understood without reference to the whole, which is thus regarded as greater than the sum of its parts.

Holobiont - an ecological unit of different species living together in symbiosis. The term is frequently used for the unit of a host and its associated microbiota but can be extended to larger scales. Whether or to what extent holobionts are also a unit of evolution is still a matter of debate (Douglas and Werren 2016).

Hologenome - the combined genomes of the host and all members of its microbiota; Rosenberg et al. 2007a; Zilber-Rosenberg and Rosenberg 2008)

Horizontal transmission - acquisition of the associated microbiome from the environment (e.g. Myers and Rothman 1995; Roughgarden 2019, preprint).

Host - the largest or dominant partner in a holobiont.

Infochemical - a chemical compound, usually diffusible, that carries information on the environment, such as the presence of other organisms, and can be used to mediate inter- and intraspecific communication (Dicke and Sabelis 1988).

Microbial gardening - the act of frequently releasing growth-enhancing or inhibiting chemicals or metabolites that favor the development of a microbial community beneficial to the host (see e.g. Saha and Weinberger 2019).

Microbiome - the combined genetic information encoded by the microbiota; may also refer to the microbiota itself or the microbiota and its environment (see Marchesi and Ravel 2015).

Microbiota - all microorganisms present in a particular environment or associated with a particular host (see Marchesi and Ravel 2015).

Nested ecosystems - a view of ecosystems where each individual system, like a "Russian doll", can be decomposed into smaller systems and/or considered part of a larger system, all of which still qualify as ecosystems (e.g. McFall-Ngai et al. 2013).

Phagocytosis - a process by which a eukaryotic cell ingests other cells or solid particles, e.g. the engulfing of symbionts by sponges (Leys, Kahn, et al. 2018).

Peer) reviewing PDF | (2020:09:53081:1:2:NEW 22 Dec 2020) 
157

158

159

160

161

162

163

164

165

166

167

168

169

170

171

172

173

174

175

176

177

178

179

180

181

182

183

184

185

186

187

188

189

190

191

192

193

194

195

196

Phycosphere - the physical envelope surrounding a phytoplankton cell; usually rich in organic matter (see Amin et al. 2012).

Phylosymbiosis - congruence in the phylogeny of different hosts and the composition of their associated microbiota (Brooks, Kohl, et al. 2016).

Rasputin effect - the phenomenon that commensals and mutualists can become parasitic in certain conditions (Overstreet and Lotz 2016); after the Russian monk Rasputin who became the confidant of the Tsar of Russia, but later helped bring down the Tsar's empire during the Russian revolution.

Sponge loop - sponges efficiently recycle dissolved organic matter turning it into detritus that becomes food for other consumers (de Goeij, van Oevelen, et al. 2013).

Symbiont - an organism living in symbiosis; usually refers to the smaller/microbial partners living in mutualistic relationships (see also host), but also includes organisms in commensalistic and parasitic relationships.

Symbiosis - a close and lasting or recurrent (e.g. over generations) relationship between organisms living together; usually refers to mutualistic relationships, but also includes commensalism and parasitism.

Vertical transmission - acquisition of the associated microbiome by a new generation of hosts from the parents (as opposed to horizontal transmission; e.g. Roughgarden 2019, preprint).

\section{Rationale, intended audience, and survey methodology}

The idea of considering organisms in connection with the complex microbial communities they are associated with is a concept rapidly gaining in importance in a wide field of life and environmental sciences. It goes along with an increasing awareness that many organisms depend on complex interactions with their symbiotic microbiota for different aspects of their life, even though the extent of dependencies may vary strongly (Hammer, Sanders, et al. 2019). The host and its associated microbiota are considered a single ecological unit, the holobiont. This implies a real paradigm shift. Marine environments harbor most of the diversity of life in terms of the number of lineages that coexist, and the constant presence of surrounding water as a potential carrier of metabolites but also microbes facilitates tight interactions between these lineages, making a "holistic" view of these environments and the organisms that inhabit them particularly important.

This paper is intended for both scientists seeking an overview of recent developments in marine holobiont research and as a reference for policymakers. We review the state of the art in the field research and identify key challenges, possible solutions, and opportunities in the field. Our work is based on the result of a foresight workshop hosted in March 2018, which brought together an interdisciplinary group of 31 scientists. These scientists were selected for their complementary expertise in philosophy, evolution, computer sciences, marine biology, ecology, chemistry, microscopy, and microbiology, as well as for their work with a wide range of different model systems from phytoplankton, via macroalgae, corals, and sponges, to bacterial communities of hydrothermal vents. After a three-day brainstorming session, the resulting ideas and discussions were divided into different topics, and groups of two or more scientists were appointed to draft each section, each based on their expertise in the field, their knowledge of the

Peer) reviewing PDF | (2020:09:53081:1:2:NEW 22 Dec 2020) 
197

198

199

\section{0}

201

202

203

204

205

206

207

208

209

210

211

212

213

214

215

216

217

218

219

220

221

222

223

224

225

226

227

228

229

230

231

232

233

234

235

literature, and literature searches. The assembled paper was then corrected and completed by the entire consortium.

\section{Marine holobionts from their origins to the present}

\section{The history of the holobiont concept}

Holism is a philosophical notion first proposed by Aristotle in the $4^{\text {th }}$ century BC. It states that systems should be studied in their entirety, with a focus on the interconnections between their various components rather than on the individual parts (Met. Z.17, 1041b11-33). Such systems have emergent properties that result from the behavior of a system that is 'larger than the sum of its parts'. However, a major shift away from holism occurred during the Age of "Enlightenment" when the dominant thought summarized as "dissection science" was to focus on the smallest component of a system as a means of understanding it.

The idea of holism started to regain popularity in biology when the endosymbiosis theory was first proposed by Mereschkowski (1905) and further developed by Wallin (1925). Still accepted today, this theory posits a single origin for eukaryotic cells through the symbiotic assimilation of prokaryotes to form first mitochondria and later plastids (the latter through several independent symbiotic events) via phagocytosis (reviewed in Archibald 2015). These ancestral and founding symbiotic events, which prompted the metabolic and cellular complexity of eukaryotic life, most likely occurred in the ocean (Martin, Baross, et al. 2008).

Despite the general acceptance of the endosymbiosis theory, the term 'holobiosis' or 'holobiont' did not immediately enter the scientific vernacular. It was coined independently by Adolf Meyer-Abich in 1943 (Baedke, Fábregas-Tejeda, et al. 2020) and by Lynn Margulis in 1990, who proposed that evolution has worked mainly through symbiosis-driven leaps that merged organisms into new forms, referred to as 'holobionts', and only secondarily through gradual mutational changes (Margulis and Fester 1991, O'Malley 2017). However, the concept was not widely used until it was co-opted by coral biologists over a decade later. Corals and dinoflagellate algae of the family Symbiodiniaceae are one of the most iconic examples of symbioses found in nature; most corals are incapable of long-term survival without the products of photosynthesis provided by their endosymbiotic algae. Rohwer et al. (2002) were the first to use the word "holobiont" to describe a unit of selection sensu Margulis (Rosenberg, Koren, et al. 2007b) for corals, where the holobiont comprised the cnidarian polyp (host), algae of the family Symbiodiniaceae, various ectosymbionts (endolithic algae, prokaryotes, fungi, other unicellular eukaryotes), and viruses.

Although initially driven by studies of marine organisms, much of the research on the emerging properties and significance of holobionts has since been carried out in other fields of research: the microbiota of the rhizosphere of plants or the animal gut became predominant models and have led to an ongoing paradigm shift in agronomy and medical sciences (Bulgarelli, Schlaeppi, et al. 2013, Shreiner, Kao, et al. 2015, Faure, Simon, et al. 2018). Holobionts occur in terrestrial and aquatic habitats alike, and several analogies between these ecosystems can be made. For example, in all of these habitats, 
236

237

238

239

240

241

242

243

244

245

246

247

248

249

250

251

252

253

254

255

256

257

258

259

260

261

262

263

264

265

266

267

268

269

270

271

272

273

274

275

276

interactions within and across holobionts such as induction of chemical defenses, nutrient acquisition, or biofilm formation are mediated by chemical cues and signals in the environment, dubbed infochemicals (Loh, Pierson, et al. 2002, Harder, Campbell, et al. 2012, Rolland, Stien, et al. 2016, Saha, Berdalet, et al. 2019). Nevertheless, we can identify two major differences between terrestrial and aquatic systems. First, the physicochemical properties of water result in higher chemical connectivity and signaling between macro- and micro-organisms in aquatic or moist environments. In marine ecosystems, carbon fluxes also appear to be swifter and trophic modes more flexible, leading to higher plasticity of functional interactions across holobionts (Mitra, Flynn, et al. 2013). Moreover, dispersal barriers are usually lower, allowing for faster microbial community shifts in marine holobionts (Kinlan and Gaines 2003, Burgess, Baskett, et al. 2016, Martin-Platero, Cleary, et al. 2018). Secondly, phylogenetic diversity at broad taxonomic scales (i.e. supra-kingdom, kingdom and phylum levels), is higher in aquatic realms compared to land, with much of the aquatic diversity yet to be uncovered (de Vargas, Audic, et al. 2015, Thompson, Sanders, et al. 2017), especially marine viruses (Middelboe and Brussaard 2017, Gregory, Zayed, et al. 2019). The recent discovery of such astonishing marine microbial diversity in parallel with the scarcity of marine holobiont research suggest a high potential for complex cross-lineage interactions yet to be explored in marine holobionts (Figure 1).

The boundaries of holobionts are usually delimited by a physical gradient, which corresponds to the area of local influence of the host, e.g. in unicellular algae the so-called phycosphere (Seymour, Amin, et al. 2017). However, they may also be defined in a context-dependent way as a 'Russian Matryoshka doll', setting the boundaries of the holobiont depending on the interactions and biological functions that are being considered. Thus holobionts may encompass all levels of host-symbiont associations from intimate endosymbiosis with a high degree of co-evolution up to the community and ecosystem level; a concept referred to as "nested ecosystems" (Figure 2; McFall-Ngai et al. 2013; Pita et al. 2018).

Such a conceptual perspective raises fundamental questions not only regarding the interaction between the different components of holobionts and processes governing their dynamics, but also of the relevant units of selection and the role of co-evolution. For instance, plant and animal evolution involves new functions co-constructed by members of the holobiont or elimination of functions redundant among them (Selosse, Bessis, et al. 2014), and it is likely that these processes are also relevant in marine holobionts. Rosenberg et al. (2010) and Rosenberg and Zilber-Rosenberg (2018) argued that all animals and plants can be considered holobionts, and thus advocate the hologenome theory of evolution, suggesting that natural selection acts at the level of the holobiont and its hologenome. This interpretation of Margulis' definition of a 'holobiont' considerably broadened fundamental concepts in evolution and speciation and has not been free of criticism (Douglas and Werren 2016), especially when applied at the community or ecosystem level (Moran and Sloan 2015). More recently, it has been shown that species that interact indirectly with the host can also be important in shaping coevolution within mutualistic multipartner assemblages (Guimarães, Pires, et al. 2017). Thus, the holobiont concept and the underlying complexity of holobiont systems should be better defined and further considered when addressing evolutionary and ecological questions.

\section{Marine holobiont models}

Peer) reviewing PDF | (2020:09:53081:1:2:NEW 22 Dec 2020) 
Today, an increasing number of marine model organisms, both unicellular and multicellular, are being used in holobiont research (Figure 1), often with different emphasis and levels of experimental control, but altogether covering a large range of scientific topics. Here, we provide several illustrative examples of this diversity and some of the insights they have provided, distinguishing between "environmental models", chosen for their environmental, evolutionary, economical, or ecological importance, or for historical reasons, but in which microbiome composition is not or only partially controlled, and "controlled bi- or trilateral associations", which can be kept separately from their symbionts under laboratory conditions and are particularly useful to develop functional approaches and study the mechanisms of symbiotic interactions.

Environmental models: Within the animal kingdom, and in addition to corals and sponges, which will be discussed below, the discovery of deep-sea hydrothermal vents revealed symbioses of animals with chemosynthetic bacteria that have later been found in many other marine ecosystems (Dubilier, Bergin, et al. 2008, Rubin-Blum, Antony, et al. 2019) and frequently exhibit high levels of metabolic and taxonomic diversity (Duperron, Halary, et al. 2008, Petersen, Kemper, et al. 2016, Ponnudurai, Kleiner, et al. 2017). In the SAR supergroup, in addition to well-known models such as diatoms, radiolarians and foraminiferans, both heterotrophic protist dwellers harboring endosymbiotic microalgae, are emerging as ecological models for unicellular photosymbiosis due to their ubiquitous presence in the world's oceans (Decelle, Colin, et al. 2015, Not, Probert, et al. 2016). Among the haptophytes, the cosmopolitan Emiliania huxleyi, promoted by associated bacteria (Seyedsayamdost, Case, et al. 2011, Segev, Wyche, et al. 2016), produces key intermediates in the carbon and sulfur biogeochemical cycles, making it an important model phytoplankton species. Finally, within the Archaeplastida, the siphonous green alga Bryopsis is an example of a model that harbors heterotrophic endosymbiotic bacteria, some of which exhibit patterns of coevolution with their hosts (Hollants, Leliaert, et al. 2013)

Controlled bi- or trilateral associations: Only a few models, covering a small part of the overall marine biodiversity, are currently being cultivated ex-situ and can be used in fully controlled experiments, where they can be cultured aposymbiotically. The flatworm Symsagittifera (= Convoluta) roscoffensis (Arboleda, Hartenstein, et al. 2018), the sea anemone Exaiptasia (Baumgarten, Simakov, et al. 2015, Wolfowicz, Baumgarten, et al. 2016), the upside-down jellyfish Cassiopea (Ohdera, Abrams, et al. 2018), and their respective intracellular green and dinoflagellate algae have, in addition to corals, become models for fundamental research on evolution of metazoan-algal photosymbiosis. In particular, the sea anemone Exaiptasia has been used to explore photobiology disruption and restoration of cnidarian symbioses (Lehnert et al. 2012). The Vibrio-squid model provides insights into the effect of microbiota on animal development, circadian rhythms, and immune systems (McFall-Ngai 2014). The unicellular green alga Ostreococcus, an important marine primary producer, has been shown to exchange vitamins with specific associated bacteria (Cooper, Kazamia, et al. 2019). The green macroalga Ulva mutabilis has enabled the exploration of bacteria-mediated growth and morphogenesis including the identification of original chemical interactions in the holobiont (Wichard 2015, Kessler, Weiss, et al. 2018). Although the culture conditions in these highly-controlled model systems differ from the natural environment, these systems are essential to gain elementary mechanistic understanding of the functioning, the roles, and the evolution of marine holobionts. 


\section{The influence of marine holobionts on ecological processes}

319

320

321

322

323

324

325

326

327

328

329

330

331

332

333

334

335

336

337

338

339

340

341

342

343

344

345

346

347

348

349

350

351

352

353

354

355

356
Work on model systems has demonstrated that motile and macroscopic marine holobionts can act as dissemination vectors for geographically restricted microbial taxa. Pelagic mollusks or vertebrates are textbook examples of high dispersal capacity organisms (e.g. against currents and through stratified water layers). It has been estimated that fish and marine mammals may enhance the original dispersion rate of their microbiota by a factor of 200 to 200,000 (Troussellier, Escalas, et al. 2017) and marine birds may even act as bio-vectors across ecosystem boundaries (Bouchard Marmen, Kenchington, et al. 2017). This host-driven dispersal of microbes can include non-native or invasive species as well as pathogens (Troussellier, Escalas, et al. 2017).

A related ecological function of holobionts is their potential to sustain rare species. Hosts provide an environment that favors the growth of specific microbial communities distinct from the surrounding environment (including rare microbes). They may, for instance, provide a nutrient-rich niche in the otherwise nutrient-poor surroundings (Smriga, Sandin, et al. 2010, Webster, Taylor, et al. 2010, Burke, Thomas, et al. 2011, Chiarello, Auguet, et al. 2018).

Lastly, biological processes regulated by microbes are important drivers of global biogeochemical cycles (Falkowski, Fenchel, et al. 2008, Madsen 2011, Anantharaman, Brown, et al. 2016). In the open ocean, it is estimated that symbioses with the cyanobacterium UCYN-A contribute $\sim 20 \%$ to total $\mathrm{N}_{2}$ fixation (Thompson, Foster, et al. 2012, Martínez-Pérez, Mohr, et al. 2016). In benthic systems, sponges and corals may support entire ecosystems via their involvement in nutrient cycling thanks to their microbial partners (Raina, Tapiolas, et al. 2009, Fiore, Jarett, et al. 2010, Cardini, Bednarz, et al. 2015, Pita, Rix, et al. 2018), functioning as sinks and sources of nutrients. In particular the "sponge loop" recycles dissolved organic matter and makes it available to higher trophic levels in the form of detritus (de Goeij, van Oevelen, et al. 2013, Rix, de Goeij, et al. 2017). In coastal sediments, bivalves hosting methanogenic archaea have been shown to increase the benthic methane efflux by a factor of up to eight, potentially accounting for $9.5 \%$ of total methane emissions from the Baltic Sea (Bonaglia, Brüchert, et al. 2017). Such impressive metabolic versatility is accomplished because of the simultaneous occurrence of disparate biochemical machineries (e.g. aerobic and anaerobic pathways) in individual symbionts, providing new metabolic abilities to the holobiont, such as the synthesis of specific essential amino acids, photosynthesis, or chemosynthesis (Dubilier, Bergin, et al. 2008, Venn, Loram, et al. 2008). Furthermore, the interaction between host and microbiota can potentially extend the metabolic capabilities of a holobiont in a way that augments its resilience to environmental changes (Berkelmans and van Oppen 2006, Gilbert, McDonald, et al. 2010, Dittami, Duboscq-Bidot, et al. 2016, Shapira 2016, Godoy, Bartomeus, et al. 2018), or allow it to cross biotope boundaries (e.g. Woyke 2006) and colonize extreme environments (Bang, Dagan, et al. 2018). Holobionts thus contribute to marine microbial diversity and possibly resilience in the context of global environmental changes (Troussellier, Escalas, et al. 2017) and it is paramount to include the holobiont concept in predictive models that investigate the consequences of human impacts on the marine realm and its biogeochemical cycles.

Peer) reviewing PDF | (2020:09:53081:1:2:NEW 22 Dec 2020) 


\section{Challenges and opportunities in marine holobiont research}

\section{Marine holobiont assembly and regulation}

359

360

361

362

363

364

365

366

367

368

369

370

371

372

373

374

375

376

377

378

379

380

381

382

383

384

385

386

387

388

389

390

391

392

393

394

395

Two critical challenges partially addressed by using model systems are 1) to decipher the factors determining holobiont composition and 2) to elucidate the impacts and roles of the different partners in these complex systems over time. Some marine organisms such as bivalves transmit part of the microbiota maternally (Bright and Bulgheresi 2010, Funkhouser and Bordenstein 2013). In other marine holobionts, vertical transmission may be weak and inconsistent, whereas mixed modes of transmission (vertical and horizontal) or intermediate modes (pseudo-vertical, where horizontal acquisition frequently involves symbionts of parental origin) are more common (Björk, Díez-Vives, et al. 2019). Identifying the factors shaping holobiont composition and understanding their evolution is highly relevant for marine organisms given that most marine hosts display a high specificity for their microbiota and even patterns of phylosymbiosis (Brooks, Kohl, et al. 2016, Kazamia, Helliwell, et al. 2016, Pollock, McMinds, et al. 2018), despite a highly connected and microbe-rich environment.

During microbiota transmission (whether vertical or horizontal), selection by the host and/or by other components of the microbiome, is a key process in establishing or maintaining a holobiont microbial community that is distinct from the environment. The immune system of the host, e.g. via the secretion of specific antimicrobial peptides (Franzenburg, Walter, et al. 2013, Zheng, Liwinski, et al. 2020), is one way of performing this selection in both marine and terrestrial holobionts.

Another way of selecting a holobiont microbial community is by chemically mediated microbial gardening. This concept has been demonstrated for land plants, where root exudates manipulate microbiome composition (Lebeis, Paredes, et al. 2015). In marine environments, the phylogenetic diversity of hosts and symbionts suggests both conserved and marine-specific chemical interactions, but studies are still in their infancy. For instance, seaweeds can chemically garden beneficial microbes, facilitating normal morphogenesis and increasing disease resistance (Kessler, Weiss, et al. 2018, Saha and Weinberger 2019), and seaweeds and corals structure their surface-associated microbiome by producing chemo-attractants and anti-bacterial compounds (Harder, Campbell, et al. 2012, Ochsenkühn, SchmittKopplin, et al. 2018). There are fewer examples of chemical gardening in unicellular hosts, but it seems highly likely that similar processes are in place (Gribben, Nielsen, et al. 2017, Cirri and Pohnert 2019).

In addition to selection, ecological drift, dispersal and evolutionary diversification have been proposed as key processes in community assembly, but are difficult to estimate in microbial communities (Nemergut, Schmidt, et al. 2013). The only data currently at our disposal to quantify these processes are the diversity and distribution of microbes. Considering the high connectivity of aquatic environments, differences in marine microbial communities are frequently attributed to a combination of selection and drift, rather than limited dispersal (e.g. Burke, Steinberg, et al. 2011), a conclusion which, in the future, could be refined by conceptual models developed for instance for soil microbial communities (Stegen et al. 2013; Dini-Andreote et al. 2015). Diversification is mainly considered in the sense of coevolution or adaptation to host selection, which may also be driven by the horizontal acquisition of genes. However, cospeciation is challenging to prove (de Vienne, Refrégier, et al. 2013, Moran and Sloan 2015) and only

Peer) reviewing PDF | (2020:09:53081:1:2:NEW 22 Dec 2020) 
396

397

398

399

400

401

402

403

404

405

406

407

408

409

410

411

412

413

414

415

416

417

418

419

420

421

422

423

424

425

426

427

428

429

430

431

432

433

434

435

few studies have examined this process in marine holobionts to date, each focused on a restricted number of actors (e.g. Peek et al. 1998; Lanterbecq et al. 2010).

Perturbations in the transmission or the recruitment of the microbiota can lead to dysbiosis, and eventually microbial infections (Selosse, Bessis, et al. 2014, de Lorgeril, Lucasson, et al. 2018). Dysbiotic microbial communities are frequently determined by stochastic processes and thus display higher variability in their composition than those of healthy individuals. This observation in line with the "Anna Karenina principle" (Zaneveld, McMinds, et al. 2017), although there are exceptions to this rule (e.g. Marzinelli et al. 2015). A specific case of dysbiosis is the so-called "Rasputin effect" where benign endosymbionts opportunistically become detrimental to the host due to processes such as reduction in immune response under food deprivation, coinfections, or environmental pressure (Overstreet and Lotz 2016). Many diseases are now interpreted as the result of a microbial imbalance and the rise of opportunistic or polymicrobial infections upon host stress (Egan and Gardiner 2016). For instance in reefbuilding corals, warming destabilizes cnidarian-dinoflagellate associations, and some beneficial Symbiodiniacea strains switch their physiology and sequester more resources for their own growth at the expense of the coral host, leading to coral bleaching and even death (Baker, Freeman, et al. 2018).

Increasing our knowledge on the contribution of these processes to holobiont community assembly in marine systems is a key challenge, which is of particular urgency today in the context of ongoing global change. Moreover, understanding how the community and functional structure of resident microbes are resilient to perturbations remains critical to predict and promote the health of their host and the ecosystem. Yet, the contribution of the microbiome is still missing in most quantitative models predicting the distribution of marine macro-organisms, or additional information on biological interactions would be required to make the former more accurate (Bell, Rovellini, et al. 2018).

\section{Integrating marine model systems with large-scale studies}

By compiling a survey of the most important trends and challenges in the field of marine holobiont research (Figure 3), we identified two distinct opinion clusters: one focused on mechanistic understanding and work with model systems whereas another targets large-scale and heterogeneous data set analyses and predictive modeling. This illustrates that, on the one hand, the scientific community is interested in the establishment of models for the identification of specific molecular interactions between marine organisms at a given point in space and time, up to the point of synthesizing functional mutualistic communities in vitro (Kubo, Hosoda, et al. 2013). On the other hand, another part of the community is moving towards global environmental sampling schemes such as the TARA Oceans expedition (Pesant, Not, et al. 2015) or the Ocean Sampling Day (Kopf, Bicak, et al. 2015), and towards long-term data series (e.g. Wiltshire et al. 2010; Harris 2010). What emerges as both lines of research progress is the understanding that small-scale functional studies in the laboratory are inconsequential unless made applicable to ecologically-relevant systems. At the same time, and despite the recent advances in community modeling (Ovaskainen, Tikhonov, et al. 2017), hypotheses drawn from large scale-studies remain correlative and require experimental validation of the mechanisms driving the observed processes. We illustrate the importance of integrating both approaches in Figure 3 , where the node 
436

437

438

439

440

441

442

443

444

445

446

447

448

449

450

451

452

453

454

455

456

457

458

459

460

461

462

463

464

465

466

467

468

469

470

471

472

473

474

475

476

related to potential applications was perceived as a central hub at the interface between mechanistic understanding and predictive modeling.

A successful example merging both functional and large-scale approaches, are the root nodules of legumes, which harbor nitrogen-fixing bacteria. In this system, the functioning, distribution, and to some extent the evolution of these nodules, are now well understood (Epihov, Batterman, et al. 2017). The integration of this knowledge into agricultural practices has led to substantial yield improvements (e.g. Kavimandan 1985; Alam et al. 2015). In the more diffuse and partner-rich system of mycorrhizal symbioses between plant roots and soil fungi, a better understanding of the interactions has also been achieved via the investigation of environmental diversity patterns in combination with experimental culture systems with reduced diversity (van der Heijden, Martin, et al. 2015).

We advocate the implementation of comparable efforts in marine sciences through interdisciplinary research combining physiology, biochemistry, ecology, and computational modeling. A key factor will be the identification and development of tractable model systems for keystone holobionts that allow hypotheses generated by large-scale data sets to be tested in controlled experiments. Such approaches will enable the identification of organismal interaction patterns within holobionts and nested ecosystems. In addition to answering fundamental questions, they will help address the ecological, societal, and ethical issues that arise from attempting to actively manipulate holobionts (e.g. in aquaculture, conservation, and invasion) in order to enhance their resilience and protect them from the impacts of global change (Llewellyn, Boutin, et al. 2014).

\section{Emerging methodologies to approach the complexity of holobiont partnerships}

As our conceptual understanding of the different levels of holobiont organization evolves, so does the need for multidisciplinary approaches and the development of tools and technologies to handle the unprecedented amount of data and their integration into dedicated ecological and evolutionary models. Here, progress is often fast-paced and provides exciting opportunities to address some of the challenges in holobiont research.

A giant technological stride has been the explosion of affordable '-omics' technologies allowing molecular ecologists to move from metabarcoding (i.e. sequencing of a taxonomic marker) to metagenomics or single-cell genomics, metatranscriptomics, and metaproteomics, thus advancing our research from phylogenetic analyses of the holobiont to analyses capable of making predictions about the functions carried out by different components of the holobiont (Bowers et al. 2017; Meng et al. 2018; Figure 4). These approaches are equally useful in marine and in terrestrial environments, but the scarcity of well-studied lineages in the former makes the generation of good annotations and reference databases challenging for marine biologists. Metaproteomics combined with stable isotope fingerprinting can help study the metabolism of single lineages within the holobiont (Kleiner, Dong, et al. 2018). In parallel, metametabolomics approaches have advanced over the last decades, and can be used to unravel the chemical interactions between partners. One limitation particularly relevant to marine systems is that many compounds are often not referenced in the mostly terrestrial-based databases, although recent technological advances such as molecular networking and meta-mass shift chemical profiling to identify relatives of known molecules may help to overcome this challenge (Hartmann, Petras, et al. 2017).

Peer) reviewing PDF | (2020:09:53081:1:2:NEW 22 Dec 2020) 
477

478

479

480

481

482

483

484

485

486

487

488

489

490

491

492

493

494

495

496

497

498

499

500

501

502

503

504

505

506

507

508

509

510

511

512

513

514

515

516

517

518

A further challenge in holobiont research is to identify the origin of compounds among the different partners of the holobionts and to determine their involvement in the maintenance and performance of the holobiont system. Well-designed experimental setups may help answer some of these questions (e.g. Quinn et al. 2016), but they will also require high levels of replication in order to represent the extensive intra-species variability found in marine systems. Recently developed in vivo and in situ imaging techniques combined with metabolomicomics can provide small-scale spatial and qualitative information (origin, distribution, and concentration of a molecule or nutrient), shedding new light on the contribution of each partner of the holobiont system at the molecular level (e.g. Geier et al. 2020). The combination of stable isotope labelling and chemical imaging (mass spectrometry imaging such as secondary ion mass spectrometry and matrix-assisted laser desorption ionization, and synchrotron X-ray fluorescence) is particularly valuable in this context, as it enables the investigation of metabolic exchange between the different compartments of a holobiont (Musat, Musat, et al. 2016, Raina, Clode, et al. 2017). Finally, three-dimensional electron microscopy may help evaluate to what extent different components of a holobiont are physically integrated (Colin, Coelho, et al. 2017, Decelle, Stryhanyuk, et al. 2019), where high integration is one indication of highly specific interactions. All of these techniques can be employed in both marine and terrestrial systems, but in marine systems the high phylogenetic diversity of organisms adds to the complexity of adapting and optimizing these techniques.

One consequence of the development of such new methods is the feedback they provide to improve existing models or to develop entirely new ones, e.g. by conceptualizing holobionts as the combination of the interactions between the host and its microbiota (Skillings 2016, Berry and Loy 2018), or by redefining boundaries between the holobiont and its environment (Zengler and Palsson 2012). Such models may incorporate metabolic complementarity between different components of the holobiont (Dittami, Eveillard, et al. 2014, Bordron, Latorre, et al. 2016), e.g. enabling the prediction of testable metabolic properties depending on holobiont composition (Burgunter-Delamare, KleinJan, et al. 2020), or simulate microbial communities starting from different cohorts of randomly generated microbes for comparison with actual metatranscriptomics and/or metagenomics data (Coles, Stukel, et al. 2017).

A side-effect of these recent developments has been to move holobiont research away from laboratory culture-based experiments. We argue that maintaining or even extending cultivation efforts, possibly via the implementation of "culturomics" approaches as successfully carried out for the human gut microbiome (Lagier, Armougom, et al. 2012), remains essential to capture the maximum holobiont biodiversity possible and will facilitate the experimental testing of hypotheses and the investigation of physiological mechanisms. A striking example of the importance of laboratory experimentation is the way germ-free mice re-inoculated with cultivated bacteria (the so-called gnotobiotic mice) have contributed to the understanding of interactions within the holobiont in animal health, physiology, and behavior (e.g. Neufeld et al. 2011; Faith et al. 2014; Selosse et al. 2014). In terms of gnotobiotic marine organisms there are several examples of microalgae that can be cultured axenically, but gnotobiotic multicellular organisms are rare. One example is the green alga Ulva mutabilils, which can be rendered axenic based on the movement of its spores and has been used to study the effects of bacteria-produced morphogens (Spoerner, Wichard, et al. 2012). There are also examples of gnotobiotic marine fish and mollusks (Marques, Ollevier, et al. 2006). However, in many cases, not all associated microorganisms can be controlled leaving researchers with aposymbiotic cultures (i.e. cultures without the main symbiont(s), as e.g. for the sea anemone Exaiptasia) (Lehnert, Mouchka, et al. 2014). Innovations in cultivation techniques

Peer) reviewing PDF | (2020:09:53081:1:2:NEW 22 Dec 2020) 
519 for axenic (or germ-free) hosts or in microbial cultivation such as microfluidic systems (e.g. Pan et al. 2011) 520 and cultivation chips (Nichols, Cahoon, et al. 2010) may provide a way to obtain a wider spectrum of pure

521 cultures. Yet, bringing individual components of holobionts into cultivation can still be a daunting 522 challenge due to the strong interdependencies between organisms as well as the existence of yet 523 unknown metabolic processes that may have specific requirements. In this context, single-cell '-omics' 524 analyses can provide critical information on some of the growth requirements of the organisms, and 525 complement approaches of high-throughput culturing (Gutleben, Chaib De Mares, et al. 2018).

$526 \quad$ Established cultures can then be developed into model systems, e.g. by genome sequencing and 527 the development of genetic tools to move towards mechanistic understanding and experimental testing 528 of hypothetical processes within the holobiont derived from environmental meta'-omics' approaches. In 529 this context, CRISPR/cas9 is a particularly promising tool for the genetic modification of both host and 530 symbiont organisms, and has been established for a few marine model systems, including diatoms, 531 cnidarians, annelids, echinoderms, and chordates (Momose and Concordet 2016), although this tool has 532 not, to the best of our knowledge, been used so far to decipher host symbiont interactions. 'Omics' 533 techniques, coupled to efforts in adapting these genetic tools, have the potential to broaden the range of 534 available models, enabling a better understanding of the functioning of marine holobionts and their 535 536

\section{Ecosystem services and holobionts in natural and managed systems}

538

539

540

541

542

543

544

545

546

547

548

549

550

551

552

553

554

555

556

557

558

559

A better understanding of marine holobionts will likely have direct socio-economic consequences for coastal marine ecosystems, estimated to provide services worth almost 50 trillion (1012) US\$ per year (Costanza, de Groot, et al. 2014). Most of the management practices in marine systems have so far been based exclusively on the biology and ecology of macro-organisms. A multidisciplinary approach that provides mechanistic understanding of habitat-forming organisms as holobionts will ultimately improve the predictability and management of coastal ecosystems. For example, host-associated microbiota could be integrated in biomonitoring programs as proxies used to assess the health of ecosystems. Microbial shifts and dysbiosis constitute early warning signals that may allow managers to predict potential impacts and intervene more rapidly and effectively (van Oppen, Gates, et al. 2017, Marzinelli, Qiu, et al. 2018).

One form of intervention could be to promote positive changes of host-associated microbiota, in ways analogous to the use of pre- and/or probiotics in humans (Singh, Ahmad, et al. 2013) or inoculation of beneficial microbes in plant farming (Berruti, Lumini, et al. 2015, van der Heijden, Martin, et al. 2015). In macroalgae, beneficial bacteria identified from healthy seaweed holobionts could be used as biological control agents and applied to diseased plantlets in order to suppress the growth of bacteria detrimental to the host and to prevent disease outbreaks in aquaculture settings. In addition to bacteria, these macroalgae frequently host endophytic fungi that may have protective functions for the algae (PorrasAlfaro and Bayman 2011, Vallet, Strittmatter, et al. 2018). Host-associated microbiota could also be manipulated to shape key phenotypes in cultured marine organisms. For example, specific bacteria associated with microalgae may enhance algal growth (Amin, Green, et al. 2009, Kazamia, Aldridge, et al. 2012, Le Chevanton, Garnier, et al. 2013), increase lipid content (Cho, Ramanan, et al. 2015), and participate in the bioprocessing of algal biomass (Lenneman, Wang, et al. 2014). More recently, the active

Peer) reviewing PDF | (2020:09:53081:1:2:NEW 22 Dec 2020) 
560 modification of the coral microbiota has even been advocated as a means to boost the resilience of the 561 holobiont to climate change (van Oppen, Oliver, et al. 2015, Peixoto, Rosado, et al. 2017), an approach

562 which would, however, bear a high risk of unanticipated and unintended side effects.

563 Also, holistic approaches could be implemented in the framework of fish farms. Recent 564 developments including integrated multi-trophic aquaculture, recirculating aquaculture, offshore 565 aquaculture, species selection, and breeding increase yields and reduce the resource constraints and 566 environmental impacts of intensive aquaculture (Klinger and Naylor 2012). However, the intensification 567 of aquaculture often goes hand in hand with increased amounts of disease outbreaks both in industry and 568 wild stocks. A holistic microbial management approach, e.g. by reducing the use of sterilization 569 procedures and favoring the selection of healthy and stable microbiota consisting of slow-growing K570 strategists, may provide an efficient solution to these latter problems, reducing the sensitivity of host to opportunistic pathogens (De Schryver and Vadstein 2014).

Nevertheless, when considering their biotechnological potential, it should also be noted that marine microbiota are likely vulnerable to anthropogenic influences and that their deliberate engineering, 574 introduction from exotic regions (often hidden in their hosts), or inadvertent perturbations may have profound, and yet entirely unknown, consequences for marine ecosystems. Terrestrial environments provide numerous examples of unwanted plant expansions or ecosystem perturbations linked to microbiota (e.g. Dickie et al. 2017), and cases where holobionts manipulated by human resulted in pests (e.g. Clay and Holah 1999) call for a cautious and ecologically-informed evaluation of holobiont-based technologies in marine systems.

\section{Conclusions}

581

582

583

584

585

586

587

588

589

590

591

592

593

594

595

596

597

598
Marine ecosystems represent highly connected reservoirs of largely unexplored biodiversity. They are of critical importance to feed the ever-growing world population, constitute significant players in global biogeochemical cycles but are also threatened by human activities and global change. In order to unravel some of the basic principles of life and its evolution, and to protect and sustainably exploit marine natural resources, it is paramount to consider the complex biotic interactions that shape the marine communities and their environment. The scope of these interactions ranges from simple molecular signals between two partners, via complex assemblies of eukaryotes, prokaryotes, and viruses with one or several hosts, to entire ecosystems. Accordingly, current key questions in marine holobiont research cover a wide range of topics: What are the exchanges that occur between different partners of the holobiont, and how do they condition their survival, dynamics and evolution? What are the cues and signals driving these exchanges? What are the relevant units of selection and dispersal in marine holobionts? How do holobiont systems and the interactions within them change over time and in different conditions? How do such changes impact ecological processes? How can this knowledge be applied to our benefit and where do we need to draw limits? Identifying and consolidating key model systems while adapting emerging "-omics", imaging, culturing technologies, and functional analyses via transgenesis (e.g. CRISPR/cas9) to them will be critical to the development of "holobiont-aware" ecosystem models.

The concept of holobionts represents the fundamental understanding that all living organisms have intimate connections with their immediate neighbors, which may impact all aspects of their biology. 
599 We believe that this concept of holobionts will be most useful if used with a degree of malleability, 600 enabling us to define units of interacting organisms that are most suitable to answer specific questions.

601 The consideration of the holobiont concept marks a paradigm shift in biological and environmental 602 sciences, but only if scientists work together as an (inter)active and transdisciplinary community bringing 603 together holistic and mechanistic views. This will result in tangible outcomes including a better 604 understanding of evolutionary and adaptive processes, improved modeling of habitats and understanding 605 of biogeochemical cycles, as well as application of the holobiont concept in aquaculture and ecosystem 606 management projects.

\section{Acknowledgements}

This paper is based on the results of a foresight workshop funded by the EuroMarine network, Sorbonne University, and the UMRs 8227 and 7144 of the Roscoff Biological Station. We are grateful to

610 Catherine Boyen for useful advice and helpful discussions. We thank Sylvie Kwayeb-Fagon for workshop 611 facilitation; Maryvonne Saout and Léna Corre for administrative support; and Marc Trousselier, Sébastien

612 Villéger, Arthur Escalas, Yvan Bettarel, Thierry Bouvier for help writing a part of the manuscript. EMM was 613 partially funded by an Australian Research Council Discovery Project (DP180104041), and JP was partially 614 funded by the Galician Innovation Agency (IN607A 2017/4). The work of SD ad CL was partially funded by 615 the ANR project IDEALG (ANR-10-BTBR-04). CG, CL, and SD received funding from the European Union's 616 Horizon 2020 research and innovation program under the Marie Sklodowska-Curie grant agreement 617 number 624575 (ALFF). The work of FN was partially funded by the ANR project IMPEKAB (ANR-15-CE02618 001). UC was partially funded by the Research Council of Lithuania project INBALANCE (09.3.3-LMT-K-712619 01-0069). JD was supported by the LabEx GRAL (ANR-10-LABX-49-01) and Pôle CBS from the University of 620 Grenoble Alpes. PC received support from the European Union's Horizon 2020 research and innovation 621 program through the SponGES project (grant agreement No. 679849). EKAZ was funded by a Marie Curie 622 Individual Fellowship (Horizon 2020, IRONCOMM). AHE was supported by Portuguese national funds from 623 FCT - Foundation for Science and Technology through projects UID/Multi/04326/2019 and 624 UIDB/04326/2020. This document reflects only the authors' view and the Executive Agency for Small and 625 Medium-sized Enterprises (EASME) is not responsible for any use that may be made of the information it 626 contains. This manuscript has been peer-reviewed and recommended by Peer Community In Ecology 627 (https://doi.org/10.24072/pci.ecology.100045)

\section{Conflict of interest disclosure}

\section{References}

632 Alam, F., Kim, T.Y., Kim, S.Y., Alam, S.S., Pramanik, P., Kim, P.J. \& Lee, Y.B. 2015. Effect of molybdenum on 
633

634

635

636

637

638

639

640

641

642

643

644

645

646

647

648

649

650

651

652

653

654

655

656

657

658

659

660

661

662

663

664

665

666

667

668

669

670

671

672

673

674

675

676

677

678

679

680

681

682

683

684

685 nodulation, plant yield and nitrogen uptake in hairy vetch (Vicia villosa Roth). Soil Sci. Plant Nutr. 61:664-75. Amin, S.A., Green, D.H., Hart, M.C., Küpper, F.C., Sunda, W.G. \& Carrano, C.J. 2009. Photolysis of iron-siderophore chelates promotes bacterial-algal mutualism. Proc. Natl. Acad. Sci. U. S. A. 106:17071-6.

Amin, S.A., Parker, M.S. \& Armbrust, E.V. 2012. Interactions between diatoms and bacteria. Microbiol. Mol. Biol. Rev. 76:667-84.

Anantharaman, K., Brown, C.T., Hug, L.A., Sharon, I., Castelle, C.J., Probst, A.J., Thomas, B.C., Singh, A., Wilkins, M.J., Karaoz, U., Brodie, E.L., Williams, K.H., Hubbard, S.S. \& Banfield, J.F. 2016. Thousands of microbial genomes shed light on interconnected biogeochemical processes in an aquifer system. Nat. Commun. 7:13219.

Arboleda, E., Hartenstein, V., Martinez, P., Reichert, H., Sen, S., Sprecher, S. \& Bailly, X. 2018. An emerging system to study photosymbiosis, brain regeneration, chronobiology, and behavior: the marine acoel Symsagittifera roscoffensis. BioEssays. 40:1800107.

Archibald, J.M. 2015. Endosymbiosis and eukaryotic cell evolution. Curr. Biol. 25:R911-21.

Baedke, J., Fábregas-Tejeda, A. \& Nieves Delgado, A. 2020. The holobiont concept before Margulis. J. Exp. Zool. Part B Mol. Dev. Evol. 334:149-55.

Baker, D.M., Freeman, C.J., Wong, J.C.Y., Fogel, M.L. \& Knowlton, N. 2018. Climate change promotes parasitism in a coral symbiosis. ISME J. 12:921-30.

Bang, C., Dagan, T., Deines, P., Dubilier, N., Duschl, W.J., Fraune, S., Hentschel, U., Hirt, H., Hülter, N., Lachnit, T., Picazo, D., Pita, L., Pogoreutz, C., Rädecker, N., Saad, M.M., Schmitz, R.A., Schulenburg, H., Voolstra, C.R., Weiland-Bräuer, N. et al. 2018. Metaorganisms in extreme environments: do microbes play a role in organismal adaptation? Zoology. 127:1-19.

Baumgarten, S., Simakov, O., Esherick, L.Y., Liew, Y.J., Lehnert, E.M., Michell, C.T., Li, Y., Hambleton, E.A., Guse, A., Oates, M.E., Gough, J., Weis, V.M., Aranda, M., Pringle, J.R. \& Voolstra, C.R. 2015. The genome of Aiptasia, a sea anemone model for coral symbiosis. Proc. Natl. Acad. Sci. U. S. A. 112:11893-8.

Bell, J.J., Rovellini, A., Davy, S.K., Taylor, M.W., Fulton, E.A., Dunn, M.R., Bennett, H.M., Kandler, N.M., Luter, H.M. \& Webster, N.S. 2018. Climate change alterations to ecosystem dominance: how might sponge-dominated reefs function? Ecology. 99:1920-31.

Bennett, A.F., Haslem, A., Cheal, D.C., Clarke, M.F., Jones, R.N., Koehn, J.D., Lake, P.S., Lumsden, L.F., Lunt, I.D.,

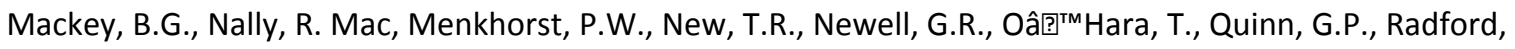
J.Q., Robinson, D., Watson, J.E.M. et al. 2009. Ecological processes: a key element in strategies for nature conservation. Ecol. Manag. Restor. 10:192-9.

Berkelmans, R. \& van Oppen, M.J.H. 2006. The role of zooxanthellae in the thermal tolerance of corals: a "nugget of hope" for coral reefs in an era of climate change. Proc. R. Soc. B Biol. Sci. 273:2305-12.

Berruti, A., Lumini, E., Balestrini, R. \& Bianciotto, V. 2015. Arbuscular mycorrhizal fungi as natural biofertilizers: let's benefit from past successes. Front. Microbiol. 6:1559.

Berry, D. \& Loy, A. 2018. Stable-isotope probing of human and animal microbiome function. Trends Microbiol. 26:999-1007.

Björk, J.R., Díez-Vives, C., Astudillo-García, C., Archie, E.A. \& Montoya, J.M. 2019. Vertical transmission of sponge microbiota is inconsistent and unfaithful. Nat. Ecol. Evol. 3:1172-83.

Bonaglia, S., Brüchert, V., Callac, N., Vicenzi, A., Chi Fru, E. \& Nascimento, F.J.A. 2017. Methane fluxes from coastal sediments are enhanced by macrofauna. Sci. Rep. 7:13145.

Bordron, P., Latorre, M., Cortés, M.-P., González, M., Thiele, S., Siegel, A., Maass, A. \& Eveillard, D. 2016. Putative bacterial interactions from metagenomic knowledge with an integrative systems ecology approach. Microbiologyopen. 5:106-17.

Bouchard Marmen, M., Kenchington, E., Ardyna, M. \& Archambault, P. 2017. Influence of seabird colonies and other environmental variables on benthic community structure, Lancaster Sound region, Canadian Arctic. J. Mar. Syst. 167:105-17.

Bowers, R.M., Doud, D.F.R. \& Woyke, T. 2017. Analysis of single-cell genome sequences of bacteria and archaea. Emerg. Top. Life Sci. 1:249-55.

Bright, M. \& Bulgheresi, S. 2010. A complex journey: transmission of microbial symbionts. Nat. Rev. Microbiol. 8:218-30.

Brooks, A.W., Kohl, K.D., Brucker, R.M., van Opstal, E.J. \& Bordenstein, S.R. 2016. Phylosymbiosis: relationships and functional effects of microbial communities across host evolutionary history. PLOS Biol. 14:e2000225.

Peer] reviewing PDF | (2020:09:53081:1:2:NEW 22 Dec 2020) 
686

687

688

689

690

691

692

693

694

695

696

697

698

699

700

701

702

703

704

705

706

707

708

709

710

711

712

713

714

715

716

717

718

719

720

721

722

723

724

725

726

727

728

729

730

731

732

733

734

735

736

737

738
Bulgarelli, D., Schlaeppi, K., Spaepen, S., Ver Loren van Themaat, E. \& Schulze-Lefert, P. 2013. Structure and functions of the bacterial microbiota of plants. Annu. Rev. Plant Biol. 64:807-38.

Burgess, S.C., Baskett, M.L., Grosberg, R.K., Morgan, S.G. \& Strathmann, R.R. 2016. When is dispersal for dispersal? Unifying marine and terrestrial perspectives. Biol. Rev. 91:867-82.

Burgunter-Delamare, B., KleinJan, H., Frioux, C., Fremy, E., Wagner, M., Corre, E., Le Salver, A., Leroux, C., Leblanc, C., Boyen, C., Siegel, A. \& Dittami, S.M. 2020. Metabolic complementarity between a brown alga and associated cultivable bacteria provide indications of beneficial interactions. Front. Mar. Sci. 7:813683.

Burke, C., Steinberg, P., Rusch, D., Kjelleberg, S. \& Thomas, T. 2011. Bacterial community assembly based on functional genes rather than species. Proc. Natl. Acad. Sci. U. S. A. 108:14288-93.

Burke, C., Thomas, T., Lewis, M., Steinberg, P. \& Kjelleberg, S. 2011. Composition, uniqueness and variability of the epiphytic bacterial community of the green alga Ulva australis. ISME J. 5:590-600.

Cardini, U., Bednarz, V.N., Naumann, M.S., van Hoytema, N., Rix, L., Foster, R.A., Al-Rshaidat, M.M.D. \& Wild, C. 2015. Functional significance of dinitrogen fixation in sustaining coral productivity under oligotrophic conditions. Proc. R. Soc. B Biol. Sci. 282:20152257.

Chiarello, M., Auguet, J.-C., Bettarel, Y., Bouvier, C., Claverie, T., Graham, N.A.J., Rieuvilleneuve, F., Sucré, E., Bouvier, T. \& Villéger, S. 2018. Skin microbiome of coral reef fish is highly variable and driven by host phylogeny and diet. Microbiome. 6:147.

Cho, D.-H., Ramanan, R., Heo, J., Lee, J., Kim, B.-H., Oh, H.-M. \& Kim, H.-S. 2015. Enhancing microalgal biomass productivity by engineering a microalgal-bacterial community. Bioresour. Technol. 175:578-85.

Cirri, E. \& Pohnert, G. 2019. Algae-bacteria interactions that balance the planktonic microbiome. New Phytol. 223:100-6.

Clay, K. \& Holah, J. 1999. Fungal endophyte symbiosis and plant diversity in successional fields. Science (80-. ). 285:1742-4.

Coles, V.J., Stukel, M.R., Brooks, M.T., Burd, A., Crump, B.C., Moran, M.A., Paul, J.H., Satinsky, B.M., Yager, P.L., Zielinski, B.L. \& Hood, R.R. 2017. Ocean biogeochemistry modeled with emergent trait-based genomics. Science (80-. ). 358:1149-54.

Colin, S., Coelho, L.P., Sunagawa, S., Bowler, C., Karsenti, E., Bork, P., Pepperkok, R. \& de Vargas, C. 2017. Quantitative 3D-imaging for cell biology and ecology of environmental microbial eukaryotes. Elife. 6:e26066.

Cooper, M.B., Kazamia, E., Helliwell, K.E., Kudahl, U.J., Sayer, A., Wheeler, G.L. \& Smith, A.G. 2019. Cross-exchange of B-vitamins underpins a mutualistic interaction between Ostreococcus tauri and Dinoroseobacter shibae. ISME J. 13:334-345.

Costanza, R., de Groot, R., Sutton, P., van der Ploeg, S., Anderson, S.J., Kubiszewski, I., Farber, S. \& Turner, R.K. 2014. Changes in the global value of ecosystem services. Glob. Environ. Chang. 26:152-8.

de Goeij, J.M., van Oevelen, D., Vermeij, M.J.A., Osinga, R., Middelburg, J.J., de Goeij, A.F.P.M. \& Admiraal, W. 2013. Surviving in a marine desert: the sponge loop retains resources within coral reefs. Science (80-. ). 342:108-10.

de Lorgeril, J., Lucasson, A., Petton, B., Toulza, E., Montagnani, C., Clerissi, C., Vidal-Dupiol, J., Chaparro, C., Galinier, R., Escoubas, J.-M., Haffner, P., Dégremont, L., Charrière, G.M., Lafont, M., Delort, A., Vergnes, A., Chiarello, M., Faury, N., Rubio, T. et al. 2018. Immune-suppression by OsHV-1 viral infection causes fatal bacteraemia in Pacific oysters. Nat. Commun. 9:4215.

De Schryver, P. \& Vadstein, O. 2014. Ecological theory as a foundation to control pathogenic invasion in aquaculture. ISME J. 8:2360-8.

de Vargas, C., Audic, S., Henry, N., Decelle, J., Mahé, F., Logares, R., Lara, E., Berney, C., Le Bescot, N., Probert, I., Carmichael, M., Poulain, J., Romac, S., Colin, S., Aury, J.-M., Bittner, L., Chaffron, S., Dunthorn, M., Engelen, S. et al. 2015. Eukaryotic plankton diversity in the sunlit ocean. Science (80-. ). 348:1261605.

de Vienne, D.M., Refrégier, G., López-Villavicencio, M., Tellier, A., Hood, M.E. \& Giraud, T. 2013. Cospeciation vs host-shift speciation: methods for testing, evidence from natural associations and relation to coevolution. New Phytol. 198:347-85.

Decelle, J., Colin, S. \& Foster, R.A. 2015. Marine protists. In Ohtsuka, S., Suzaki, T., Horiguchi, T., Suzuki, N. \& Not, F. [Eds.] Marine Protists. Springer Japan, Tokyo, pp. 465-500.

Decelle, J., Stryhanyuk, H., Gallet, B., Veronesi, G., Schmidt, M., Balzano, S., Marro, S., Uwizeye, C., Jouneau, P.-H., Lupette, J., Jouhet, J., Maréchal, E., Schwab, Y., Schieber, N.L., Tucoulou, R., Richnow, H., Finazzi, G. \& Musat, N. 2019. Algal remodeling in a ubiquitous planktonic photosymbiosis. Curr. Biol. 29:968-78.

PeerJ reviewing PDF | (2020:09:53081:1:2:NEW 22 Dec 2020) 
739

740

741

742

743

744

745

746

747

748

749

750

751

752

753

754

755

756

757

758

759

760

761

762

763

764

765

766

767

768

769

770

771

772

773

774

775

776

777

778

779

780

781

782

783

784

785

786

787

788

789

790

791
Dicke, M. \& Sabelis, M.W. 1988. Infochemical terminology: based on cost-benefit analysis rather than origin of compounds? Funct. Ecol. 2:131.

Dickie, I.A., Bufford, J.L., Cobb, R.C., Desprez-Loustau, M.-L., Grelet, G., Hulme, P.E., Klironomos, J., Makiola, A., Nuñez, M.A., Pringle, A., Thrall, P.H., Tourtellot, S.G., Waller, L. \& Williams, N.M. 2017. The emerging science of linked plant-fungal invasions. New Phytol. 215:1314-32.

Dini-Andreote, F., Stegen, J.C., van Elsas, J.D. \& Salles, J.F. 2015. Disentangling mechanisms that mediate the balance between stochastic and deterministic processes in microbial succession. Proc. Natl. Acad. Sci. USA. 112:E1326-32.

Dittami, S.M., Duboscq-Bidot, L.L., Perennou, M., Gobet, A.A., Corre, E., Boyen, C. \& Tonon, T. 2016. Host-microbe interactions as a driver of acclimation to salinity gradients in brown algal cultures. ISME J. 10:51-63.

Dittami, S.M., Eveillard, D. \& Tonon, T. 2014. A metabolic approach to study algal-bacterial interactions in changing environments. Mol. Ecol. 23:1656-60.

Douglas, A.E. \& Werren, J.H. 2016. Holes in the hologenome: why host-microbe symbioses are not holobionts. MBio. 7:e02099.

Dubilier, N., Bergin, C. \& Lott, C. 2008. Symbiotic diversity in marine animals: the art of harnessing chemosynthesis. Nat. Rev. Microbiol. 6:725-40.

Duperron, S., Halary, S., Lorion, J., Sibuet, M. \& Gaill, F. 2008. Unexpected co-occurrence of six bacterial symbionts in the gills of the cold seep mussel Idas sp. (Bivalvia: Mytilidae). Environ. Microbiol. 10:433-45.

Egan, S. \& Gardiner, M. 2016. Microbial dysbiosis: rethinking disease in marine ecosystems. Front. Microbiol. 7:991.

Epihov, D.Z., Batterman, S.A., Hedin, L.O., Leake, J.R., Smith, L.M. \& Beerling, D.J. 2017. N2-fixing tropical legume evolution: a contributor to enhanced weathering through the Cenozoic? Proc. R. Soc. B Biol. Sci. 284:20170370.

Faith, J.J., Ahern, P.P., Ridaura, V.K., Cheng, J. \& Gordon, J.I. 2014. Identifying gut microbe-host phenotype relationships using combinatorial communities in gnotobiotic mice. Sci. Transl. Med. 6:220ra11.

Falkowski, P.G., Fenchel, T. \& Delong, E.F. 2008. The microbial engines that drive Earth's biogeochemical cycles. Science (80-. ). 320:1034-9.

Faure, D., Simon, J.-C. \& Heulin, T. 2018. Holobiont: a conceptual framework to explore the eco-evolutionary and functional implications of host-microbiota interactions in all ecosystems. New Phytol. 218:1321-4.

Fiore, C.L., Jarett, J.K., Olson, N.D. \& Lesser, M.P. 2010. Nitrogen fixation and nitrogen transformations in marine symbioses. Trends Microbiol. 18:455-63.

Franzenburg, S., Walter, J., Kunzel, S., Wang, J., Baines, J.F., Bosch, T.C.G. \& Fraune, S. 2013. Distinct antimicrobial peptide expression determines host species-specific bacterial associations. Proc. Natl. Acad. Sci. 110:E37308.

Funkhouser, L.J. \& Bordenstein, S.R. 2013. Mom knows best: the universality of maternal microbial transmission. PLoS Biol. 11:e1001631.

Geier, B., Sogin, E.M., Michellod, D., Janda, M., Kompauer, M., Spengler, B., Dubilier, N. \& Liebeke, M. 2020. Spatial metabolomics of in situ host-microbe interactions at the micrometre scale. Nat. Microbiol. 1-13.

Gilbert, S.F., McDonald, E., Boyle, N., Buttino, N., Gyi, L., Mai, M., Prakash, N. \& Robinson, J. 2010. Symbiosis as a source of selectable epigenetic variation: taking the heat for the big guy. Philos. Trans. R. Soc. B Biol. Sci. 365:671-8.

Godoy, O., Bartomeus, I., Rohr, R.P. \& Saavedra, S. 2018. Towards the integration of niche and network theories. Trends Ecol. Evol. 33:287-300.

Gregory, A.C., Zayed, A.A., Conceição-Neto, N., Temperton, B., Bolduc, B., Alberti, A., Ardyna, M., Arkhipova, K., Carmichael, M., Cruaud, C., Dimier, C., Domínguez-Huerta, G., Ferland, J., Kandels, S., Liu, Y., Marec, C., Pesant, S., Picheral, M., Pisarev, S. et al. 2019. Marine DNA viral macro- and microdiversity from pole to pole. Cell. 177:1109-1123.e14.

Gribben, P.E., Nielsen, S., Seymour, J.R., Bradley, D.J., West, M.N. \& Thomas, T. 2017. Microbial communities in marine sediments modify success of an invasive macrophyte. Sci. Rep. 7:9845.

Guimarães, P.R., Pires, M.M., Jordano, P., Bascompte, J. \& Thompson, J.N. 2017. Indirect effects drive coevolution in mutualistic networks. Nature. 550:511-4.

Gutleben, J., Chaib De Mares, M., van Elsas, J.D., Smidt, H., Overmann, J. \& Sipkema, D. 2018. The multi-omics promise in context: from sequence to microbial isolate. Crit. Rev. Microbiol. 44:212-29.

PeerJ reviewing PDF | (2020:09:53081:1:2:NEW 22 Dec 2020) 
792

793

794

795

796

797

798

799

800

801

802

803

804

805

806

807

808

809

810

811

812

813

814

815

816

817

818

819

820

821

822

823

824

825

826

827

828

829

830

831

832

833

834

835

836

837

838

839

840

841

842

843

844

Hale, M.G., Lindsey, D.L. \& Hameed, K.M. 1973. Gnotobiotic culture of plants and related research. Bot. Rev. 39:261-73.

Hammer, T.J., Sanders, J.G. \& Fierer, N. 2019. Not all animals need a microbiome. FEMS Microbiol. Lett. 366.

Harder, T., Campbell, A.H., Egan, S. \& Steinberg, P.D. 2012. Chemical mediation of ternary interactions between marine holobionts and their environment as exemplified by the red alga Delisea pulchra. J. Chem. Ecol. 38:442-50.

Harris, R. 2010. The L4 time-series: the first 20 years. J. Plankton Res. 32:577-83.

Hartmann, A.C., Petras, D., Quinn, R.A., Protsyuk, I., Archer, F.I., Ransome, E., Williams, G.J., Bailey, B.A., Vermeij, M.J.A., Alexandrov, T., Dorrestein, P.C. \& Rohwer, F.L. 2017. Meta-mass shift chemical profiling of metabolomes from coral reefs. Proc. Natl. Acad. Sci. U. S. A. 114:11685-90.

Hoitink, H. \& Boehm, M. 1999. Biocontrol within the context of soil microbial communities : a substrate-dependent phenomenon. Annu. Rev. Phytopathol. 37:427-46.

Hollants, J., Leliaert, F., Verbruggen, H., De Clerck, O. \& Willems, A. 2013. Host specificity and coevolution of Flavobacteriaceae endosymbionts within the siphonous green seaweed Bryopsis. Mol. Phylogenet. Evol. 67:608-14.

Holt, E.A. \& Miller, S.W. 2010. Bioindicators: using organisms to measure environmental impacts. Nat. Educ. Knowl. 3:8.

Kavimandan, S.K. 1985. Root nodule bacteria to improve yield of wheat (Triticum aestivum L.). Springer.

Kazamia, E., Aldridge, D.C. \& Smith, A.G. 2012. Synthetic ecology - A way forward for sustainable algal biofuel production? J. Biotechnol. 162:163-9.

Kazamia, E., Helliwell, K.E., Purton, S. \& Smith, A.G. 2016. How mutualisms arise in phytoplankton communities: building eco-evolutionary principles for aquatic microbes. Ecol. Lett. 19:810-22.

Kelty, M.O. \& Cook, C.B. 1976. Survival during starvation of symbiotic, aposymbiotic, and non-symbiotic Hydra. In Coelenterate Ecology and Behavior. Springer, Boston, MA, pp. 409-14.

Kessler, R.W., Weiss, A., Kuegler, S., Hermes, C. \& Wichard, T. 2018. Macroalgal-bacterial interactions: Role of dimethylsulfoniopropionate in microbial gardening by Ulva (Chlorophyta). Mol. Ecol. 27:1808-19.

Kinlan, B.P. \& Gaines, S.D. 2003. Propagule dispersal in marine and terrestrial environments: a community perspective. Ecology. 84:2007-20.

Kleiner, M., Dong, X., Hinzke, T., Wippler, J., Thorson, E., Mayer, B. \& Strous, M. 2018. Metaproteomics method to determine carbon sources and assimilation pathways of species in microbial communities. Proc. Natl. Acad. Sci. U. S. A. 115:E5576-84.

Klinger, D. \& Naylor, R. 2012. Searching for solutions in aquaculture: charting a sustainable course. Annu. Rev. Environ. Resour. 37:247-76.

Kopf, A., Bicak, M., Kottmann, R., Schnetzer, J., Kostadinov, I., Lehmann, K., Fernandez-Guerra, A., Jeanthon, C., Rahav, E., Ullrich, M., Wichels, A., Gerdts, G., Polymenakou, P., Kotoulas, G., Siam, R., Abdallah, R.Z., Sonnenschein, E.C., Cariou, T., O'Gara, F. et al. 2015. The ocean sampling day consortium. Gigascience. 4:27.

Kubo, I., Hosoda, K., Suzuki, S., Yamamoto, K., Kihara, K., Mori, K. \& Yomo, T. 2013. Construction of bacteriaeukaryote synthetic mutualism. Biosystems. 113:66-71.

Lagier, J.C., Armougom, F., Million, M., Hugon, P., Pagnier, I., Robert, C., Bittar, F., Fournous, G., Gimenez, G., Maraninchi, M., Trape, J.F., Koonin, E. V., La Scola, B. \& Raoult, D. 2012. Microbial culturomics: Paradigm shift in the human gut microbiome study. Clin. Microbiol. Infect. 18:1185-93.

Lanterbecq, D., Rouse, G.W. \& Eeckhaut, I. 2010. Evidence for cospeciation events in the host-symbiont system involving crinoids (Echinodermata) and their obligate associates, the myzostomids (Myzostomida, Annelida). Mol. Phylogenet. Evol. 54:357-71.

Le Chevanton, M., Garnier, M., Bougaran, G., Schreiber, N., Lukomska, E., Bérard, J.-B., Fouilland, E., Bernard, O. \& Cadoret, J.-P. 2013. Screening and selection of growth-promoting bacteria for Dunaliella cultures. Algal Res. 2:212-22.

Lebeis, S.L., Paredes, S.H., Lundberg, D.S., Breakfield, N., Gehring, J., McDonald, M., Malfatti, S., Glavina del Rio, T., Jones, C.D., Tringe, S.G. \& Dangl, J.L. 2015. Salicylic acid modulates colonization of the root microbiome by specific bacterial taxa. Science (80-. ). 349:860-4.

Lehnert, E.M., Burriesci, M.S. \& Pringle, J.R. 2012. Developing the anemone Aiptasia as a tractable model for cnidarian-dinoflagellate symbiosis: the transcriptome of aposymbiotic A. pallida. BMC Genomics. 13:271.

Lehnert, E.M., Mouchka, M.E., Burriesci, M.S., Gallo, N.D., Schwarz, J.A. \& Pringle, J.R. 2014. Extensive differences

Peer] reviewing PDF | (2020:09:53081:1:2:NEW 22 Dec 2020) 
845

846

847

848

849

850

851

852

853

854

855

856

857

858

859

860

861

862

863

864

865

866

867

868

869

870

871

872

873

874

875

876

877

878

879

880

881

882

883

884

885

886

887

888

889

890

891

892

893

894

895

896

897 in gene expression between symbiotic and aposymbiotic cnidarians. G3\&amp;\#58;

Genes/Genomes/Genetics. 4:277-95.

Lenneman, E.M., Wang, P. \& Barney, B.M. 2014. Potential application of algicidal bacteria for improved lipid recovery with specific algae. FEMS Microbiol. Lett. 354:102-10.

Leys, S.P., Kahn, A.S., Fang, J.K.H., Kutti, T. \& Bannister, R.J. 2018. Phagocytosis of microbial symbionts balances the carbon and nitrogen budget for the deep-water boreal sponge Geodia barretti. Limnol. Oceanogr. 63:187202.

Llewellyn, M.S., Boutin, S., Hoseinifar, S.H. \& Derome, N. 2014. Teleost microbiomes: the state of the art in their characterization, manipulation and importance in aquaculture and fisheries. Front. Microbiol. 5:207.

Loh, J., Pierson, E.A., Pierson, L.S., Stacey, G. \& Chatterjee, A. 2002. Quorum sensing in plant-associated bacteria. Curr. Opin. Plant Biol. 5:285-90.

Madsen, E.L. 2011. Microorganisms and their roles in fundamental biogeochemical cycles. Curr. Opin. Biotechnol. 22:456-64.

Marchesi, J.R. \& Ravel, J. 2015. The vocabulary of microbiome research: a proposal. Microbiome. 3:31.

Margulis, L. \& Fester, R. 1991. Symbiosis as a Source of Evolutionary Innovation: Speciation and Morphogenesis. MIT Press. $470 \mathrm{pp}$.

Marques, A., Ollevier, F., Verstraete, W., Sorgeloos, P. \& Bossier, P. 2006. Gnotobiotically grown aquatic animals: opportunities to investigate host-microbe interactions. J. Appl. Microbiol. 100:903-18.

Martin-Platero, A.M., Cleary, B., Kauffman, K., Preheim, S.P., McGillicuddy, D.J., Alm, E.J. \& Polz, M.F. 2018. High resolution time series reveals cohesive but short-lived communities in coastal plankton. Nat. Commun. 9:266.

Martin, W., Baross, J., Kelley, D. \& Russell, M.J. 2008. Hydrothermal vents and the origin of life. Nat. Rev. Microbiol. 6:805-14.

Martínez-Pérez, C., Mohr, W., Löscher, C.R., Dekaezemacker, J., Littmann, S., Yilmaz, P., Lehnen, N., Fuchs, B.M., Lavik, G., Schmitz, R.A., LaRoche, J. \& Kuypers, M.M.M. 2016. The small unicellular diazotrophic symbiont, UCYN-A, is a key player in the marine nitrogen cycle. Nat. Microbiol. 1:16163.

Marzinelli, E.M., Campbell, A.H., Zozaya Valdes, E., Vergés, A., Nielsen, S., Wernberg, T., de Bettignies, T., Bennett, S., Caporaso, J.G., Thomas, T. \& Steinberg, P.D. 2015. Continental-scale variation in seaweed host-associated bacterial communities is a function of host condition, not geography. Environ. Microbiol. 17:4078-88.

Marzinelli, E.M., Qiu, Z., Dafforn, K.A., Johnston, E.L., Steinberg, P.D. \& Mayer-Pinto, M. 2018. Coastal urbanisation affects microbial communities on a dominant marine holobiont. Biofilms and Microbiomes. 4:1.

McFall-Ngai, M., Hadfield, M.G., Bosch, T.C.G., Carey, H. V., Domazet-Lošo, T., Douglas, A.E., Dubilier, N., Eberl, G., Fukami, T., Gilbert, S.F., Hentschel, U., King, N., Kjelleberg, S., Knoll, A.H., Kremer, N., Mazmanian, S.K., Metcalf, J.L., Nealson, K., Pierce, N.E. et al. 2013. Animals in a bacterial world, a new imperative for the life sciences. Proc. Natl. Acad. Sci. U. S. A. 110:3229-36.

McFall-Ngai, M.J. 2014. The importance of microbes in animal development: lessons from the squid-Vibrio symbiosis. Annu. Rev. Microbiol. 68:177-94.

Meng, A., Marchet, C., Corre, E., Peterlongo, P., Alberti, A., Da Silva, C., Wincker, P., Pelletier, E., Probert, I., Decelle, J., Le Crom, S., Not, F. \& Bittner, L. 2018. A de novo approach to disentangle partner identity and function in holobiont systems. Microbiome. 6:105.

Mereschkowski, C. 1905. Über Natur und Ursprung der Chromatophoren im Pflanzenreiche. Biol. Cent. 25:593604.

Meyer-Abich, A. 1943. Beiträge zur Theorie der Evolution der Organismen. I. Das typologische Grundgesetz und seine Folgerungen für Phylogenie und Entwicklungsphysiologie [Contributions to the evolutionary theory of organisms: I. The basic typological law and its implications f. Acta Biotheor. 7:1-80.

Middelboe, M. \& Brussaard, C.P.D. 2017. Marine viruses: key players in marine ecosystems. Viruses. 9:302.

Millennium Ecosystem Assessment Panel, T. 2005. Ecosystems and human well-being : synthesis / Millennium Ecosystem Assessment. Island press, Washington, USA. 1-155 pp.

Mitra, A., Flynn, K.J., Burkholder, J.M., Berge, T., Calbet, A., Raven, J.A., Granéli, E., Glibert, P.M., Hansen, P.J., Stoecker, D.K., Thingstad, F., Tillmann, U., Våge, S., Wilken, S. \& Zubkov, M. V. 2013. The role of mixotrophic protists in the biological carbon pump. Biogeosciences Discuss. 10:13535-62.

Momose, T. \& Concordet, J.-P. 2016. Diving into marine genomics with CRISPR/Cas9 systems. Mar. Genomics. 30:55-65.

Peer] reviewing PDF | (2020:09:53081:1:2:NEW 22 Dec 2020) 
898

899

900

901

902

903

904

905

906

907

908

909

910

911

912

913

914

915

916

917

918

919

920

921

922

923

924

925

926

927

928

929

930

931

932

933

934

935

936

937

938

939

940

941

942

943

944

945

946

947

948

949

950

Moran, N.A. \& Sloan, D.B. 2015. The hologenome concept: helpful or hollow? PLOS Biol. 13:e1002311.

Musat, N., Musat, F., Weber, P.K. \& Pett-Ridge, J. 2016. Tracking microbial interactions with NanoSIMS. Curr. Opin. Biotechnol. 41:114-21.

Myers, J.H. \& Rothman, L.E. 1995. Virulence and transmission of infectious diseases in humans and insects: evolutionary and demographic patterns. TREE. 10:194-8.

Nardon, P. \& Charles, H. 2001. Morphological Aspects of Symbiosis. In Symbiosis. Kluwer Academic Publishers, Dordrecht, pp. 13-44.

Nemergut, D.R., Schmidt, S.K., Fukami, T., O’Neill, S.P., Bilinski, T.M., Stanish, L.F., Knelman, J.E., Darcy, J.L., Lynch, R.C., Wickey, P. \& Ferrenberg, S. 2013. Patterns and processes of microbial community assembly. Microbiol. Mol. Biol. Rev. 77:342-56.

Neufeld, K.M., Kang, N., Bienenstock, J. \& Foster, J.A. 2011. Reduced anxiety-like behavior and central neurochemical change in germ-free mice. Neurogastroenterol. Motil. 23:255-64, e119.

Nichols, D., Cahoon, N., Trakhtenberg, E.M., Pham, L., Mehta, A., Belanger, A., Kanigan, T., Lewis, K. \& Epstein, S.S. 2010. Use of ichip for high-throughput in situ cultivation of "uncultivable" microbial species. Appl. Environ. Microbiol. 76:2445-50.

Not, F., Probert, I., Gerikas Ribeiro, C., Crenn, K., Guillou, L., Jeanthon, C. \& Vaulot, D. 2016. Photosymbiosis in marine pelagic environments. In The Marine Microbiome. Springer International Publishing, Cham, pp. 30532.

O'Malley, M.A. 2017. From endosymbiosis to holobionts: Evaluating a conceptual legacy. J. Theor. Biol. 434:34-41.

Ochsenkühn, M.A., Schmitt-Kopplin, P., Harir, M. \& Amin, S.A. 2018. Coral metabolite gradients affect microbial community structures and act as a disease cue. Commun. Biol. 1:184.

Ohdera, A.H., Abrams, M.J., Ames, C.L., Baker, D.M., Suescún-Bolívar, L.P., Collins, A.G., Freeman, C.J., GameroMora, E., Goulet, T.L., Hofmann, D.K., Jaimes-Becerra, A., Long, P.F., Marques, A.C., Miller, L.A., Mydlarz, L.D., Morandini, A.C., Newkirk, C.R., Putri, S.P., Samson, J.E. et al. 2018. Upside-down but headed in the right direction: review of the highly versatile Cassiopea xamachana system. Front. Ecol. Evol. 6:35.

Ovaskainen, O., Tikhonov, G., Norberg, A., Guillaume Blanchet, F., Duan, L., Dunson, D., Roslin, T. \& Abrego, N. 2017. How to make more out of community data? A conceptual framework and its implementation as models and software. Ecol. Lett. 20:561-76.

Overstreet, R.M. \& Lotz, J.M. 2016. Host-symbiont relationships: understanding the change from guest to pest. In Hurst, C. J. [Ed.] The Rasputin Effect: When Commensals and Symbionts Become Parasitic. Springer, Cham, pp. 27-64.

Pan, J., Stephenson, A.L., Kazamia, E., Huck, W.T.S., Dennis, J.S., Smith, A.G. \& Abell, C. 2011. Quantitative tracking of the growth of individual algal cells in microdroplet compartments. Integr. Biol. 3:1043.

Peek, A.S., Feldman, R.A., Lutz, R.A. \& Vrijenhoek, R.C. 1998. Cospeciation of chemoautotrophic bacteria and deep sea clams. Proc. Natl. Acad. Sci. 95:9962-6.

Peixoto, R.S., Rosado, P.M., Leite, D.C. de A., Rosado, A.S. \& Bourne, D.G. 2017. Beneficial microorganisms for corals (BMC): proposed mechanisms for coral health and resilience. Front. Microbiol. 8:341.

Pesant, S., Not, F., Picheral, M., Kandels-Lewis, S., Le Bescot, N., Gorsky, G., ludicone, D., Karsenti, E., Speich, S., Troublé, R., Dimier, C., Searson, S., Acinas, S.G., Bork, P., Boss, E., Bowler, C., De Vargas, C., Follows, M., Gorsky, G. et al. 2015. Open science resources for the discovery and analysis of Tara Oceans data. Sci. Data. 2:150023.

Petersen, J.M., Kemper, A., Gruber-Vodicka, H., Cardini, U., van der Geest, M., Kleiner, M., Bulgheresi, S., Mußmann, M., Herbold, C., Seah, B.K.B., Antony, C.P., Liu, D., Belitz, A. \& Weber, M. 2016. Chemosynthetic symbionts of marine invertebrate animals are capable of nitrogen fixation. Nat. Microbiol. 2:16195.

Pita, L., Rix, L., Slaby, B.M., Franke, A. \& Hentschel, U. 2018. The sponge holobiont in a changing ocean: from microbes to ecosystems. Microbiome. 6:46.

Pollock, F.J., McMinds, R., Smith, S., Bourne, D.G., Willis, B.L., Medina, M., Thurber, R.V. \& Zaneveld, J.R. 2018. Coral-associated bacteria demonstrate phylosymbiosis and cophylogeny. Nat. Commun. 9:4921.

Ponnudurai, R., Kleiner, M., Sayavedra, L., Petersen, J.M., Moche, M., Otto, A., Becher, D., Takeuchi, T., Satoh, N., Dubilier, N., Schweder, T. \& Markert, S. 2017. Metabolic and physiological interdependencies in the Bathymodiolus azoricus symbiosis. ISME J. 11:463-77.

Porras-Alfaro, A. \& Bayman, P. 2011. Hidden fungi, emergent properties: endophytes and microbiomes. Annu. Rev. Phytopathol. 49:291-315.

Peerf reviewing PDF | (2020:09:53081:1:2:NEW 22 Dec 2020) 
951

952

953

954

955

956

957

958

959

960

961

962

963

964

965

966

967

968

969

970

971

972

973

974

975

976

977

978

979

980

981

982

983

984

985

986

987

988

989

990

991

992

993

994

995

996

997

998

999

1000

1001

1002

1003

Quinn, R.A., Vermeij, M.J.A., Hartmann, A.C., Galtier d'Auriac, I., Benler, S., Haas, A., Quistad, S.D., Lim, Y.W., Little, M., Sandin, S., Smith, J.E., Dorrestein, P.C. \& Rohwer, F. 2016. Metabolomics of reef benthic interactions reveals a bioactive lipid involved in coral defence. Proc. R. Soc. B Biol. Sci. 283:20160469.

Raina, J.-B., Clode, P.L., Cheong, S., Bougoure, J., Kilburn, M.R., Reeder, A., Forêt, S., Stat, M., Beltran, V., ThomasHall, P., Tapiolas, D., Motti, C.M., Gong, B., Pernice, M., Marjo, C.E., Seymour, J.R., Willis, B.L. \& Bourne, D.G. 2017. Subcellular tracking reveals the location of dimethylsulfoniopropionate in microalgae and visualises its uptake by marine bacteria. Elife. 6:e23008.

Raina, J.-B., Tapiolas, D., Willis, B.L. \& Bourne, D.G. 2009. Coral-associated bacteria and their role in the biogeochemical cycling of sulfur. Appl. Environ. Microbiol. 75:3492-501.

Rix, L., de Goeij, J.M., van Oevelen, D., Struck, U., Al-Horani, F.A., Wild, C. \& Naumann, M.S. 2017. Differential recycling of coral and algal dissolved organic matter via the sponge loop. Funct. Ecol. 31:778-89.

Rohwer, F., Seguritan, V., Azam, F. \& Knowlton, N. 2002. Diversity and distribution of coral-associated bacteria. Mar. Ecol. Prog. Ser. 243:1-10.

Rolland, J.-L., Stien, D., Sanchez-Ferandin, S. \& Lami, R. 2016. Quorum sensing and quorum quenching in the phycosphere of phytoplankton: a case of chemical interactions in ecology. J. Chem. Ecol. 42:1201-11.

Rosenberg, E., Koren, O., Reshef, L., Efrony, R. \& Zilber-Rosenberg, I. 2007a. The role of microorganisms in coral health, disease and evolution. Nat. Rev. Microbiol. 5:355-62.

Rosenberg, E., Koren, O., Reshef, L., Efrony, R. \& Zilber-Rosenberg, I. 2007b. The hologenome theory disregards the coral holobiont: reply from Rosenberg et al. Nat. Rev. Microbiol. 5:826-826.

Rosenberg, E., Sharon, G., Atad, I. \& Zilber-Rosenberg, I. 2010. The evolution of animals and plants via symbiosis with microorganisms. Environ. Microbiol. Rep. 2:500-6.

Rosenberg, E. \& Zilber-Rosenberg, I. 2018. The hologenome concept of evolution after 10 years. Microbiome. 6:78.

Roughgarden, J. 2019. Holobiont evolution: model with vertical vs. horizontal microbiome transmission. bioRxiv. 465310.

Rubin-Blum, M., Antony, C.P., Sayavedra, L., Martínez-Pérez, C., Birgel, D., Peckmann, J., Wu, Y.-C., Cardenas, P., MacDonald, I., Marcon, Y., Sahling, H., Hentschel, U. \& Dubilier, N. 2019. Fueled by methane: deep-sea sponges from asphalt seeps gain their nutrition from methane-oxidizing symbionts. ISME J. 13:1209-25.

Saha, M., Berdalet, E., Carotenuto, Y., Fink, P., Harder, T., John, U., Not, F., Pohnert, G., Potin, P., Selander, E., Vyverman, W., Wichard, T., Zupo, V. \& Steinke, M. 2019. Using chemical language to shape future marine health. Front. Ecol. Environ. 17:530-7.

Saha, M. \& Weinberger, F. 2019. Microbial "gardening" by a seaweed holobiont: Surface metabolites attract protective and deter pathogenic epibacterial settlement. J. Ecol. 107:2255-65.

Segev, E., Wyche, T.P., Kim, K.H., Petersen, J., Ellebrandt, C., Vlamakis, H., Barteneva, N., Paulson, J.N., Chai, L., Clardy, J. \& Kolter, R. 2016. Dynamic metabolic exchange governs a marine algal-bacterial interaction. Elife. 5.

Selosse, M.-A., Bessis, A. \& Pozo, M.J. 2014. Microbial priming of plant and animal immunity: symbionts as developmental signals. Trends Microbiol. 22:607-13.

Seyedsayamdost, M.R., Case, R.J., Kolter, R. \& Clardy, J. 2011. The Jekyll-and-Hyde chemistry of Phaeobacter gallaeciensis. Nat. Chem. 3:331-5.

Seymour, J.R., Amin, S.A., Raina, J.-B. \& Stocker, R. 2017. Zooming in on the phycosphere: the ecological interface for phytoplankton-bacteria relationships. Nat. Microbiol. 2:17065.

Shapira, M. 2016. Gut microbiotas and host evolution: scaling up symbiosis. Trends Ecol. Evol. 31:539-49.

Shreiner, A.B., Kao, J.Y. \& Young, V.B. 2015. The gut microbiome in health and in disease. Curr. Opin. Gastroenterol. 31:69-75.

Singh, Y., Ahmad, J., Musarrat, J., Ehtesham, N.Z. \& Hasnain, S.E. 2013. Emerging importance of holobionts in evolution and in probiotics. Gut Pathog. 5:12.

Skillings, D. 2016. Holobionts and the ecology of organisms: multi-species communities or integrated individuals? Biol. Philos. 31:875-92.

Smriga, S., Sandin, S.A. \& Azam, F. 2010. Abundance, diversity, and activity of microbial assemblages associated with coral reef fish guts and feces. FEMS Microbiol. Ecol. 73:31-42.

Spoerner, M., Wichard, T., Bachhuber, T., Stratmann, J. \& Oertel, W. 2012. Growth and thallus morphogenesis of Ulva mutabilis (Chlorophyta) depends on a combination of two bacterial species excreting regulatory factors. J. Phycol. 48:1433-47.

Peer) reviewing PDF | (2020:09:53081:1:2:NEW 22 Dec 2020) 
1004

1005

1006

1007

1008

1009

1010

1011

1012

1013

1014

1015

1016

1017

1018

1019

1020

1021

1022

1023

1024

1025

1026

1027

1028

1029

1030

1031

1032

1033

1034

1035

1036

1037

1038

1039

1040

1041

1042

1043

1044

1045

1046

1047

1048

1049

1050
Stegen, J.C., Lin, X., Fredrickson, J.K., Chen, X., Kennedy, D.W., Murray, C.J., Rockhold, M.L. \& Konopka, A. 2013. Quantifying community assembly processes and identifying features that impose them. ISME J. 7:2069-79.

Theis, K.R. 2018. Hologenomics: systems-level host biology. mSystems. 3:e00164-17.

Thompson, A.W., Foster, R.A., Krupke, A., Carter, B.J., Musat, N., Vaulot, D., Kuypers, M.M.M. \& Zehr, J.P. 2012. Unicellular cyanobacterium symbiotic with a single-celled eukaryotic alga. Science (80-. ). 337:1546-50.

Thompson, L.R., Sanders, J.G., McDonald, D., Amir, A., Ladau, J., Locey, K.J., Prill, R.J., Tripathi, A., Gibbons, S.M., Ackermann, G., Navas-Molina, J.A., Janssen, S., Kopylova, E., Vázquez-Baeza, Y., González, A., Morton, J.T., Mirarab, S., Zech Xu, Z., Jiang, L. et al. 2017. A communal catalogue reveals Earth's multiscale microbial diversity. Nature. 551:457.

Tolstoy, L.N. 1878. Анна Каренина. Русский вестник, Moscow. 1-864 pp.

Troussellier, M., Escalas, A., Bouvier, T. \& Mouillot, D. 2017. Sustaining rare marine microorganisms: Macroorganisms as repositories and dispersal agents of microbial diversity. Front. Microbiol. 8:947.

Vallet, M., Strittmatter, M., Murúa, P., Lacoste, S., Dupont, J., Hubas, C., Genta-Jouve, G., Gachon, C.M.M., Kim, G.H. \& Prado, S. 2018. Chemically-mediated interactions between macroalgae, their fungal endophytes, and protistan pathogens. Front. Microbiol. 9:3161.

van der Heijden, M.G.A., Martin, F.M., Selosse, M.-A. \& Sanders, I.R. 2015. Mycorrhizal ecology and evolution: the past, the present, and the future. New Phytol. 205:1406-23.

van Oppen, M.J.H., Gates, R.D., Blackall, L.L., Cantin, N., Chakravarti, L.J., Chan, W.Y., Cormick, C., Crean, A., Damjanovic, K., Epstein, H., Harrison, P.L., Jones, T.A., Miller, M., Pears, R.J., Peplow, L.M., Raftos, D.A., Schaffelke, B., Stewart, K., Torda, G. et al. 2017. Shifting paradigms in restoration of the world's coral reefs. Glob. Chang. Biol. 23:3437-48.

van Oppen, M.J.H., Oliver, J.K., Putnam, H.M. \& Gates, R.D. 2015. Building coral reef resilience through assisted evolution. Proc. Natl. Acad. Sci. U. S. A. 112:2307-13.

Venn, A.A., Loram, J.E. \& Douglas, A.E. 2008. Photosynthetic symbioses in animals. J. Exp. Bot. 59:1069-80.

Wallin, I.E. 1925. On the nature of mitochondria. IX. Demonstration of the bacterial nature of mitochondria. Am. J. Anat. 36:131-49.

Webster, N.S., Taylor, M.W., Behnam, F., Lücker, S., Rattei, T., Whalan, S., Horn, M. \& Wagner, M. 2010. Deep sequencing reveals exceptional diversity and modes of transmission for bacterial sponge symbionts. Environ. Microbiol. 12:2070-82.

Wichard, T. 2015. Exploring bacteria-induced growth and morphogenesis in the green macroalga order Ulvales (Chlorophyta). Front. Plant Sci. 6:86.

Wichard, T. \& Beemelmanns, C. 2018. Role of chemical mediators in aquatic interactions across the prokaryoteeukaryote boundary. J. Chem. Ecol. 44:1008-21.

Williams, S.C.P. 2014. Gnotobiotics. Proc. Natl. Acad. Sci. U. S. A. 111:1661.

Wiltshire, K.H., Kraberg, A., Bartsch, I., Boersma, M., Franke, H.-D., Freund, J., Gebühr, C., Gerdts, G., Stockmann, K. \& Wichels, A. 2010. Helgoland Roads, North Sea: 45 years of change. Estuaries and Coasts. 33:295-310.

Wolfowicz, I., Baumgarten, S., Voss, P.A., Hambleton, E.A., Voolstra, C.R., Hatta, M. \& Guse, A. 2016. Aiptasia sp. larvae as a model to reveal mechanisms of symbiont selection in cnidarians. Sci. Rep. 6:32366.

Zaneveld, J.R., McMinds, R. \& Vega Thurber, R. 2017. Stress and stability: applying the Anna Karenina principle to animal microbiomes. Nat. Microbiol. 2:17121.

Zengler, K. \& Palsson, B.O. 2012. A road map for the development of community systems (CoSy) biology. Nat. Rev. Microbiol. 10:366-72.

Zheng, D., Liwinski, T. \& Elinav, E. 2020. Interaction between microbiota and immunity in health and disease. Cell Res. 30:492-506.

Zilber-Rosenberg, I. \& Rosenberg, E. 2008. Role of microorganisms in the evolution of animals and plants: the hologenome theory of evolution. FEMS Microbiol. Rev. 32:723-35. 


\section{Figure 1}

Partners forming marine holobionts

They are widespread across the tree of life including all kingdoms (eukaryotes, bacteria, archaea, viruses), and represent a large diversity of potential models for exploring complex biotic interactions across lineages. Plain lines correspond to holobionts referred to in the present manuscript. Dashed lines are examples of potential interactions. Photo credits: Archaeplastida - C. Leblanc, U Cardini; Cryptophyta, Excavata, Amoebozoa, Excavata, Cryptophyta - Roscoff Culture Collection; Stramenopila - C. Leblanc, S. M. Dittami; Alveolata - A. M. Lewis; Rhizaria - F. Not; Haptophyta - A. R. Taylor; Opisthonkonta - C. Frazee, NOAA Photo Library; Bacteria - E. Nelson, L. Sycuro, S. M. Dittami; Archaea - National Space Science Data Center, Xiaoyu Xiang; Viruses - M. B. Sullivan et al.. 


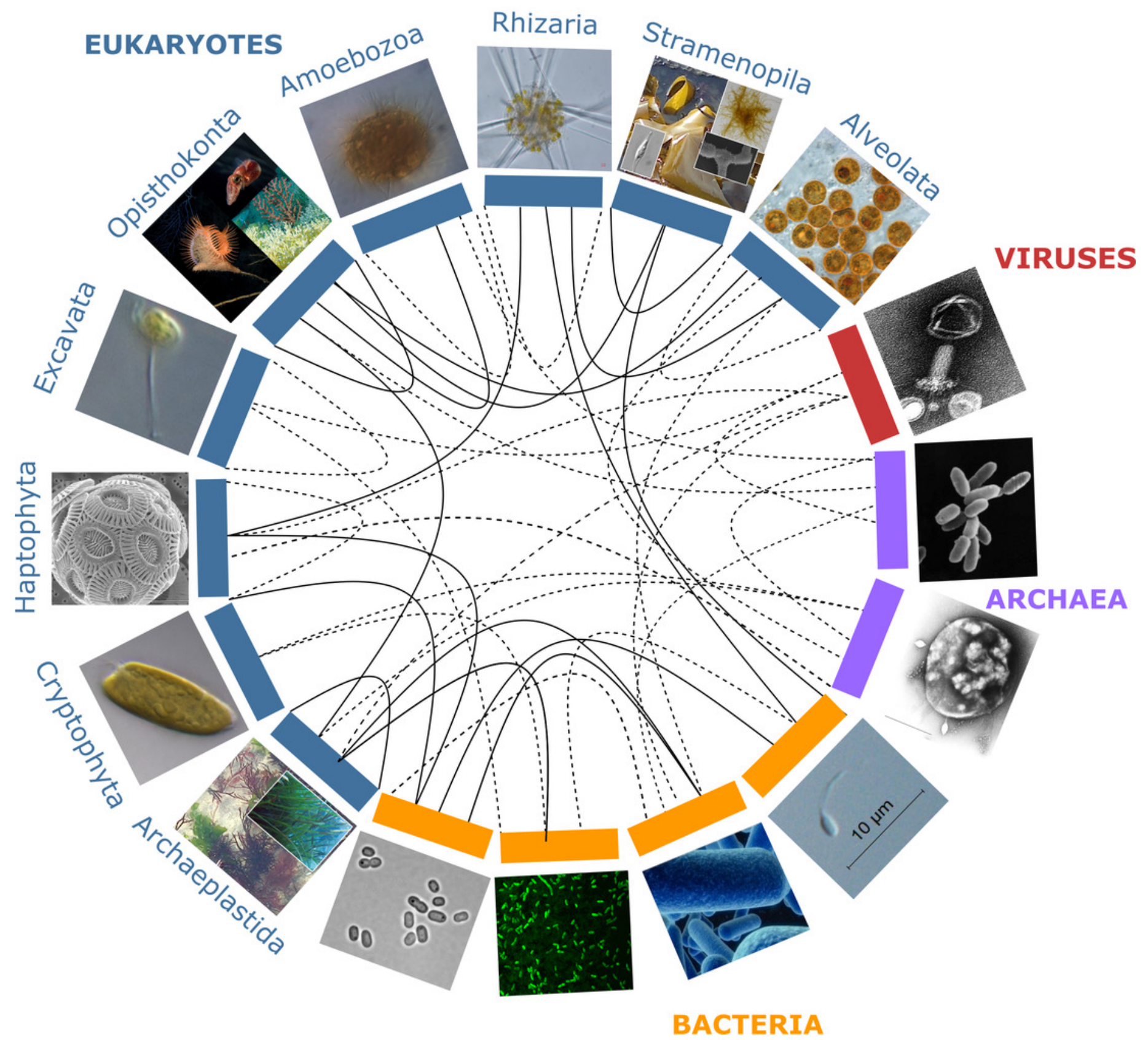




\section{Figure 2}

Schematic view of the "Russian Doll" complexity and dynamics of holobionts, according to diverse spatiotemporal scales

The host (blue circles), and associated microbes (all other shapes) including bacteria and eukaryotes that may be inside (i.e. endosymbiotic or outside the host, i.e. ectosymbiotic, are connected by either beneficial (solid orange lines), neutral (solid blue lines) or pathogenic (dashed black lines) interactions respectively. Changes from beneficial or neutral to pathogenic interactions are typical cases of dysbiosis. The different clusters can be illustrated by the following examples: 1, a model holobiont in a stable physiological condition (e.g. in controlled laboratory condition); 2 and 3, holobionts changing during their life cycle or submitted to stress conditions - examples of vertically transmitted microbes are indicated by light blue arrows; 4 and 5, marine holobionts in the context of global sampling campaigns or long-term time series - examples of horizontal transmission of microbes and holobionts are illustrated by pink arrows. 


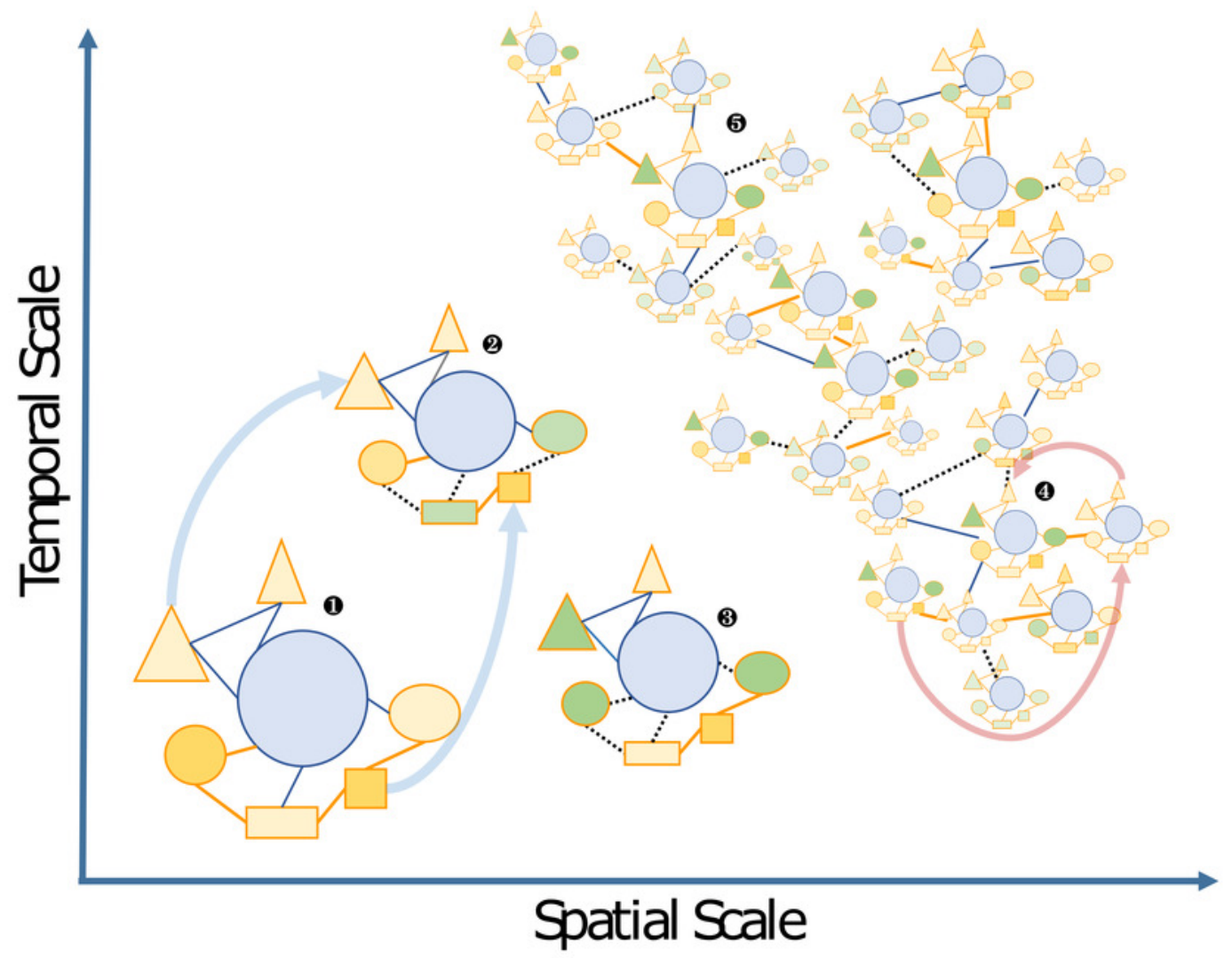




\section{Figure 3}

Mind map of key concepts, techniques, and challenges related to marine holobionts

The basis of this map was generated during the Holomarine workshop held in Roscoff in 2018 (https://www.euromarinenetwork.eu/activities/HoloMarine). The size of the nodes reflects the number of votes each keyword received from the participants of the workshop (total of 120 votes from 30 participants). The two main clusters corresponding to predictive modeling and mechanistic modeling, are displayed in purple and turquoise, respectively. Among the intermediate nodes linking these disciplines (blue) "potential use, management" was the most connected. 


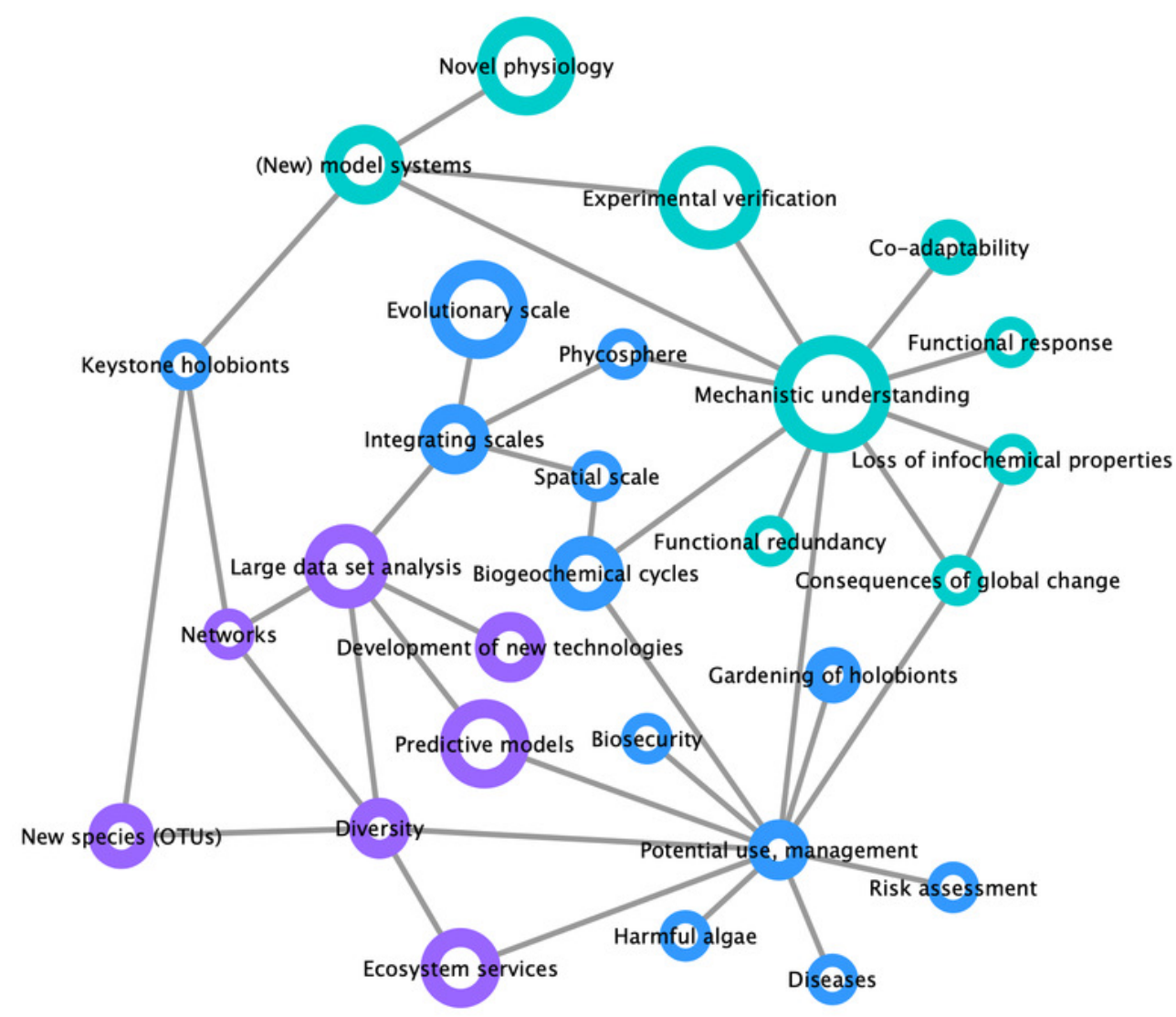




\section{Figure 4}

Impact of emerging methodologies (light green) on the main challenges in marine holobiont research identified in this paper (blue).

Turquoise and purple correspond to the two main clusters of activity identified in Figure 3.
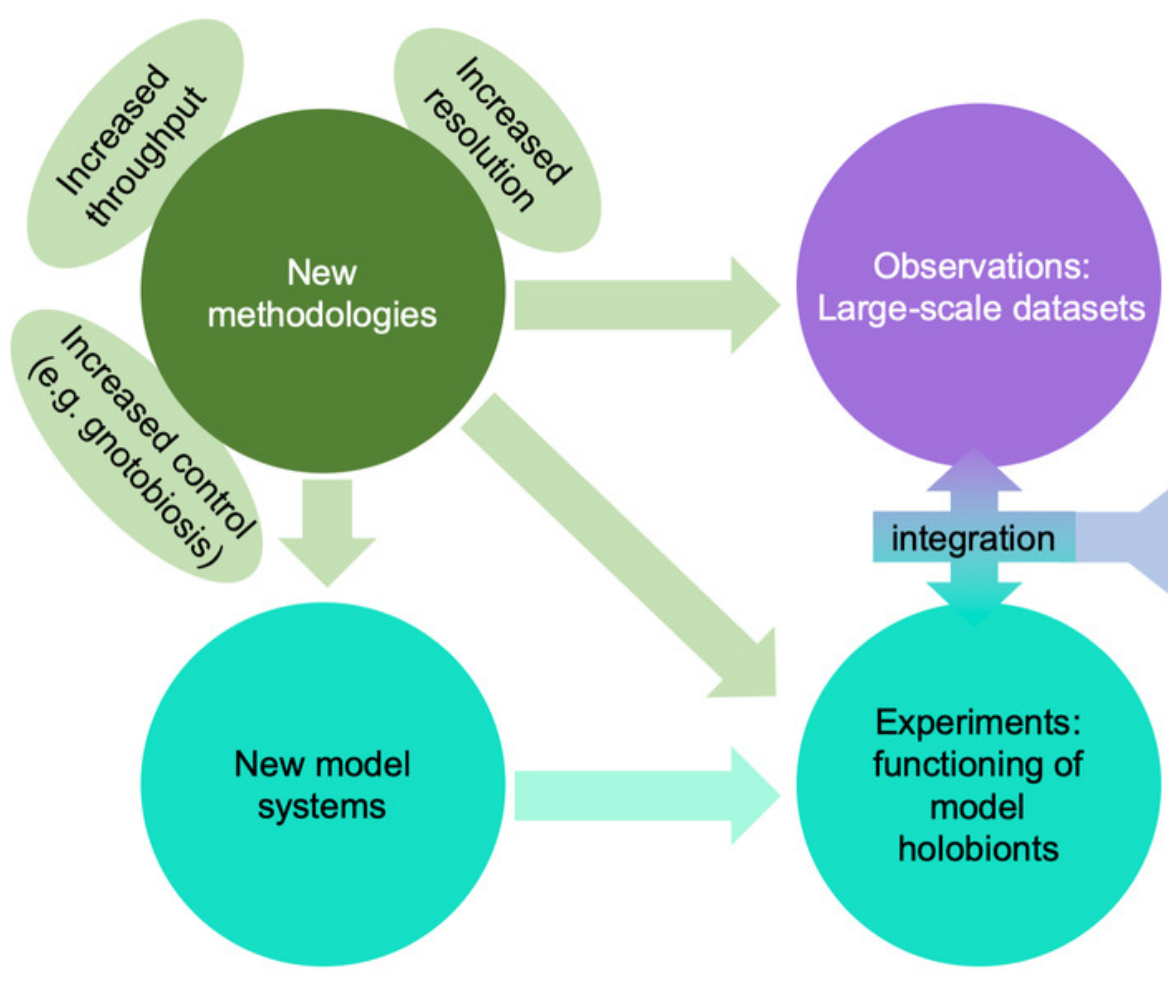

New insights

Ecological /

mathematical

models

Applications

Experiments:

functioning of

model

holobionts 